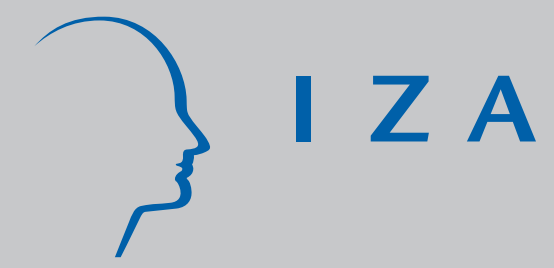

IZA DP No. 1233

Do a Few Months of Compulsory Schooling Matter?

The Education and Labour Market Impact of School Leaving Rules

Emilia Del Bono

Fernando Galindo-Rueda

August 2004 


\title{
Do a Few Months of Compulsory Schooling Matter? The Education and Labour Market Impact of School Leaving Rules
}

\author{
Emilia Del Bono \\ Queens College, University of Oxford, \\ University of California, Berkeley and IZA Bonn \\ Fernando Galindo-Rueda \\ CEP, London School of Economics and IZA Bonn
}

Discussion Paper No. 1233

August 2004

\author{
IZA \\ P.O. Box 7240 \\ 53072 Bonn \\ Germany \\ Phone: +49-228-3894-0 \\ Fax: +49-228-3894-180 \\ Email: iza@iza.org
}

\begin{abstract}
Any opinions expressed here are those of the author(s) and not those of the institute. Research disseminated by IZA may include views on policy, but the institute itself takes no institutional policy positions.

The Institute for the Study of Labor (IZA) in Bonn is a local and virtual international research center and a place of communication between science, politics and business. IZA is an independent nonprofit company supported by Deutsche Post World Net. The center is associated with the University of Bonn and offers a stimulating research environment through its research networks, research support, and visitors and doctoral programs. IZA engages in (i) original and internationally competitive research in all fields of labor economics, (ii) development of policy concepts, and (iii) dissemination of research results and concepts to the interested public.
\end{abstract}

IZA Discussion Papers often represent preliminary work and are circulated to encourage discussion. Citation of such a paper should account for its provisional character. A revised version may be available directly from the author. 
IZA Discussion Paper No. 1233

August 2004

\section{ABSTRACT \\ Do a Few Months of Compulsory Schooling Matter? The Education and Labour Market Impact of School Leaving Rules*}

This paper contributes to the understanding of how compulsory schooling regulations affect educational attainment and subsequent labour market outcomes. It uses valuable information from a natural experiment driven by rules that allow for variation in legal dropout dates. Since the school leaving rule bites in the middle of a school year cohort, our identification approach is immune to other relative age/peer effects. Information on the precise month of birth enables us to show that students compelled to stay on in education as a result of this compulsory school leaving rule attain higher qualification levels and see their participation and employment probability as adults enhanced. We show that the estimated genuine impact of attaining an academic qualification on participation and employment is always statistically significant, in particular for women, although IV coefficients are usually below OLS estimates.

JEL Classification: I2, C13, J24

Keywords: education, school leaving rules, instrumental variables, participation, employment

Corresponding author:

Fernando Galindo-Rueda

Centre for Economic Performance

London School of Economics

London WC2A 2AE

United Kingdom

Email: f.galindo-rueda@Ise.ac.uk

\footnotetext{
* This research has benefited from funding by a British Academy Research Grant and H.M. Treasury's Evidence Based Policy Fund. We thank Ghazala Azmat, Tanita Casci, Chris Crowe, Jim Foreman and Anna Vignoles for helpful discussions and Julian Austin from DfES for providing us with special tabulations from the Youth Cohort Study of England and Wales. The usual disclaimer applies.
} 


\section{Introduction}

There is substantial evidence suggesting that the amount of schooling experienced by an individual has a positive effect on test score results, qualification attainment and labour market performance. It would therefore seem advisable to encourage all individuals to stay on longer in education, particularly those mostly likely to drop out at the first opportunity. This has been the basic principle guiding compulsory schooling law reforms that have taken place over the last century and a half across many countries all over the world.

However, recent evidence suggests that factors other than length of schooling per se may interact with children's ability to learn and therefore affect their economic potential. It has been suggested, for example, that variation in the relative age of a child within her school year combined with fixed date examination schedules may arbitrarily hurt some groups. Furthermore, the existence of multiple school entry and leaving dates, often implemented such that children born in different months of the year accumulate the same amount of schooling and reach the same age at the time of entry into the labour market, may provide some children with the incentive to leave full-time education before completing even the lowest qualification level on offer by the educational system. One may therefore ask whether changes in the policies governing schooling entry and exit dates may enhance some children's educational attainment and their labour market prospects.

An interesting dichotomy can be found in the literature. On the one hand, educational studies have been preoccupied with determining the importance of age ank (i.e. relative maturity) effects on children's early achievement. In England and Wales, for example, there is a growing body of evidence showing that season of birth affects early school attainment even after controlling for differences in the length of schooling caused by the interaction between season of birth and policies governing school entry dates. According to these studies, children who are the youngest in the age group tend to perform less well at school, are more likely to be referred for special educational needs (Sharp and Benefield, 1995) and are less likely to play football professionally (Dudink, 1994). Moreover, while it is possible to argue that small differences in schooling caused by different entry dates become less important 
once children progress towards higher grades and change schools, it is still possible that within class (i.e. school cohort) age rank effects play an important role later on in the development of children's skills although no firm empirical evidence has been provided in this respect as yet. Economic studies, on the other hand, have mainly focused on establishing the effect of length of schooling on educational achievement and labour market outcomes caused by the interplay of birth dates and school leaving rules assuming that relative age effects fade out at a later stage. The influential and path breaking study by Angrist and Krueger (1991) identified the effect of compulsory schooling onto educational and labour market outcomes using the fact that fixed entry dates into schooling, combined with the existence of a compulsory schooling age, allow the oldest individuals in the class to leave school before completing a grade.

The paper by Angrist and Krueger (1991) has been the focus of considerable attention and subsequently criticised on a number of fronts. Besides statistical problems affecting the property of IV estimators with weak instruments (Bound, Jaeger and Baker, 1995), and the weak identification result under non-parametric conditions (Chesher, 2004), several authors have criticised the assumption that birth date is not directly correlated with the outcome subject to investigation, namely, individual wages. The basic argument is that schooling may well not be the only mechanism through which birth date can affect wage outcomes. For example, Bound and Jaeger (1996) have argued convincingly that certain mental health problems show dependence with birth date and influence school performance. Erik Plug (2001) finds evidence of a season of birth effect on school performance that cannot be explained by compulsory schooling legislation in the Netherlands.

In the US context, fixed schooling entry dates imply that even a small variation in birth dates can lead to up to a year difference in schooling amongst individuals who do not stay on beyond the compulsory age. If younger individuals within a school year cohort are less physically developed, and less likely to have acquired the skills to succeed in scholastic competitive hurdles that determine the level of educational attainment, there is no reason why this disadvantage may not extend itself to aspects such as self-motivation, which are thought to have a direct impact on later performance in life in general and the labour market in particular. 
As we show in Section 2, an IV strategy based on month of birth as the key identification assumption and which does not take into account age rank effects is likely to underestimate the impact of schooling on various indicators of individual labour market performance. In contrast, our analysis uses a particular feature of the rules regulating school leaving dates in England and Wales in order to identify the effect of compulsory schooling onto children's educational attainment and labour market outcomes even in the presence of long-lasting age rank effects.

As we will see in Section 3, we can safely assume that individuals born in the middle of the school year are identical in all aspects, including maturity within the classroom. However, because of the existence of multiple school leaving dates, these children are allowed to leave school at different dates. Using a sample of individuals born in England and Wales from 1957 to 1974 taken from the Labour Force Survey, it is possible to show that the oldest in this group are consistently less likely to achieve any academic qualification.

In Section 4 we identify the effect of schooling caused by this particular compulsory schooling rule on labour market outcomes such as the individual's participation status and employment probability. As we carry out our analysis separately on women and men, a gender dimension emerges from our work and, consistently with other studies, we find that education is in general a more important driver of employment and participation for women than it is for men. As discussed in Section 5, our results suggest that the effect of schooling on women is lower than what traditionally estimated through OLS, but always statistically significant. Only effects on male activity border statistical insignificance. We further investigate variation in the effects of education by cohort and calendar time, to go on to discuss potential variation by unobservable characteristics. The main lesson from our paper is that compulsory schooling regulations have the potential to benefit individuals' labour market prospects by enhancing the skills of those at the low-end of educational attainment distribution. Given the short length of the additional schooling spell induced by the rules we analyse, we can hypothesise that the benefit is highly dependent on the link between the extra schooling period and the acquisition of key educational qualifications at the end of the school year. 


\section{Compulsory schooling and date of birth}

In this paper we exploit a feature of the British educational system previously ignored in the Economics of Education literature. The natural experiment that is induced by the presence of heterogeneous school leaving rules for students in their last year of compulsory schooling allows us to identify an exogenous source of variation in educational attainment regarding the estimation of the effect of qualification attainment on labour market outcomes.

An international readership may be particularly aware of the general features of compulsory schooling considered in the highly influential paper by Angrist and Krueger (1991). Their approach shows that compulsory schooling rules operate in two steps. First of all, entry rules determine what school year or class an individual belongs to according to her own date of birth. Secondly, depending on the prevailing legal school leaving age in the individual's state of residence, she is allowed to leave school immediately after she has attained that age. In other words, if the state's minimum school leaving age is 16 , an individual can drop out from school right after her $16^{\text {th }}$ birthday. ${ }^{1}$ Within this framework, older individuals within a class are not "forced" to stay until completing the full grade, whereas their younger peers will be compelled to stay on and attain that year's grade.

The basic identification argument is that children born late in the year will be very similar to children born early in the following year, but schooling rules will imply a different compulsory length of schooling given the variation in age (up to a year) at the point of starting date at school and the common age at which they can drop out. The effect of schooling on labour market outcomes can be identified by a comparison of outcomes between these two groups, relative to their schooling differences, provided these two groups' only systematic dissimilarity is due to the impact of the compulsory schooling rules on educational outcomes.

\footnotetext{
${ }^{1}$ As Angrist and Krueger (1991) note, there are some exceptions to this. In Wisconsin and Texas, for example, students are required to complete the school term in which they reach the legal dropout age.
} 
The problems with this approach are clearly acknowledged by Angrist and Krueger (1991). They mention other possible effects of season of birth on the outcome of interest through channels that are not accounted for by the schooling measure considered in their analysis, but largely dismiss the importance of these effects. On the contrary, it can be argued that by pooling together individuals from different age groups into a same class, schooling laws can pose an extra challenge for younger students within a class. To address this question, Strom (2003) explores the strict enrolment and promotion rules in Norway to estimate the effect of age at school entry on reading achievement tests from PISA. He shows that the youngest children face a disadvantage in reading compared to older classmates. Age can thus have an independent educational impact through compulsory schooling other than the one due to school leaving rules. Given the existence of this additional educational impact, there are grounds for questioning whether these relative age impacts can persist into adulthood and manifest themselves into different labour market outcomes. The presence of these effects would seriously undermine the validity of the instrumental variable approach followed by Angrist and Krueger (1991).

In order to illustrate this point, let us consider a simple, additive model of completed schooling:

$$
s_{i}=\chi\left(c s_{i}\right)+\delta \cdot m_{i}+\Psi\left(z_{i}\right)+X_{i} \gamma+\varepsilon_{i},
$$

where total schooling $s_{i}$ depends on (1) a function of the level of compulsory schooling $c s_{i}$ that an individual must necessarily complete according to existing rules, (2) the relative maturity $m_{i}$ of the individual within his class/school-year, (3) the date of birth $z_{i}$, (4) a set of covariates $X_{i}$ and a stochastic error term $\varepsilon_{i}$. Within the US context, compulsory schooling varies with date of birth because of school entry rules that create a discontinuity between December and the following January. Compulsory schooling is then determined by the difference between the state's school leaving age and the individual specific age in the school entry date.

Let us assume for simplicity that we can observe the exact date of birth for an individual, we can then establish that an individual's length of compulsory schooling 
is a non-linear function of her date of birth, continuous everywhere except for the date that is used to separate students into schoolyear groups, which we denote as $Z^{*}$. The difference in compulsory schooling for individuals born immediately before and after $31^{\text {st }}$ December in the US would then be $\lim _{z_{i} \rightarrow Z^{*-}} c s_{i}\left(z_{i}\right)-\lim _{z_{i} \rightarrow Z^{*+}} c s_{i}\left(z_{i}\right)=12$ months. However, something similar occurs to relative maturity within class, so that the difference becomes $\lim _{z_{i} \rightarrow Z^{*_{-}}} m_{i}\left(z_{i}\right)-\lim _{z_{i} \rightarrow Z^{*_{+}}} m_{i}\left(z_{i}\right)=-12$ months when we assign value 0 to the youngest in the class and 12 to the oldest. If we assume that the expectation of all other effects - observable and unobservable - is continuous with respect to date of birth, then a comparison of educational attainment between those born immediately before and after $31^{\text {st }}$ December will provide the sample analogue of:

$s^{-}-s^{+} \equiv \lim _{z_{i} \rightarrow Z^{*-}} E\left[s_{i} \mid z_{i}\right]-\lim _{z_{i} \rightarrow Z^{*_{+}}} E\left[s_{i} \mid z_{i}\right]=\left(\chi^{-}-\chi^{+}\right)+\delta\left(m^{-}-m^{+}\right)$.

It is easy to note that this approach would underestimate the true effect of compulsory schooling $\chi^{-}-\chi^{+}$on completed schooling or any related attainment variable if relative maturity really matters $(\delta \neq 0)$. The implications of this result for the identification of the labour market effect of an educational treatment are important, as we now turn to discuss.

Let us consider now a labour market outcome of interest $p_{i}$ as a function of schooling $s_{i}$, date of birth, the vector of observable covariates $X_{i}$, and an error term.

$$
p_{i}=\rho \cdot s_{i}+X_{i} \beta+\lambda\left(z_{i}\right)+\omega_{i} .
$$

Whilst it is certainly plausible to believe that relative maturity effects tend to fade away as individuals age, there is considerable uncertainty as to whether this or is not the case. ${ }^{2}$

\footnotetext{
${ }^{2}$ This hypothesis is certainly not testable if schooling is endogenous and no other instruments are available. In the US context of Angrist and Krueger (1991), it would not be surprising to find that the over-identification null hypothesis is not rejected since over-identification is only attained through a repetition of the same instrument over different years. With sufficiently stable parameters, the estimated coefficients under alternative "exclusions" would then be likely to provide very similar results and therefore not reject the null.
} 
Comparing the labour market outcome for people born after and before $31^{\text {st }}$ December would yield:

$$
\begin{aligned}
& \lim _{\tau \rightarrow 0}\left\{E\left[p_{i} \mid z+\tau\right]-E\left[p_{i} \mid z-\tau\right]\right\}= \\
& =\rho \cdot\left(\lim _{\tau \rightarrow 0}\left\{E\left[s_{i} \mid z+\tau\right]-E\left[s_{i} \mid z-\tau\right]\right\}\right)+\lim _{\tau \rightarrow 0}\left\{E\left[\omega_{i} \mid z+\tau\right]-E\left[\omega_{i} \mid z-\tau\right]\right\} \\
& =\rho \cdot D_{S}+D_{\omega} .
\end{aligned}
$$

As a result, the Wald discontinuity estimator would capture the sample analogue of:

$$
\hat{\rho}_{\text {Wald }} \Rightarrow \frac{p^{-}-p^{+}}{s^{-}-s^{+}}=\frac{\rho \cdot D_{S}+D_{\omega}}{D_{S}}=\rho+\frac{D_{\omega}}{\left(\chi^{-}-\chi^{+}\right)+\delta \cdot\left(m^{-}-m^{+}\right)}
$$

In this case the IV strategy would provide consistent estimates of the parameter of interest only if the maturity effect is properly excluded from the labour market outcome generating process (i.e. if $D_{\omega}=0$ ). Moreover, equation (2.5) makes clear that a second and related problem is that even small deviations from this assumption whatever the sign - will provide larger biases because the denominator in the second term would tend to be smaller as the maturity effect is likely to reduce the educational "advantage" that December-born individuals have vis à vis those born in January. We might think of this as an additional "weakness" of the identification and estimation approach when season of birth is used as an instrument.

The ideal way to address this problem is to find a different value (or set of values) of birth dates $z^{\prime}$ for which the maturity effects can be differenced out in the schooling specification $\lim _{\tau \rightarrow 0}\left\{m_{i}\left(z^{\prime}+\tau\right)-m_{i}\left(z^{\prime}-\tau\right)\right\}=0$ and also from the labour market outcome process $\lim _{\tau \rightarrow 0}\left\{E\left[\omega_{i} \mid z^{\prime}+\tau\right]-E\left[\omega_{i} \mid z^{\prime}-\tau\right]\right\}=0$. In the next section, we argue this is indeed possible using data for England and Wales and taking into account its own rules regulating the end of compulsory schooling. 


\section{The educational effects of compulsory school leaving rules}

\subsection{Compulsory schooling in England and Wales}

In Great Britain, children must be in full-time education between the ages of five and sixteen. The starting age of five was set by the 1870 Education Act and has remained unchanged since then. The current school leaving age of 16 was increased from 15 by the Raising of the School Leaving Age (RoSLA) Order of 1972 for England and Wales. This order built on previous legislation in the 1944 "Butler" Education Act, which foresaw a two-step increase in the age of compulsory schooling from the 1944 level of 14. The first of these steps took place in 1947 with the raising of the school leaving age to 15 , though it would still take 15 years before the intended leaving age of 16 was reached in 1973, the year immediately after the RoSLA order. ${ }^{3}$

In England and Wales, the implementation of compulsory schooling differs from the US framework in that an individual is generally not deemed to have attained the age of compulsory schooling (16 since 1973), and therefore allowed to leave school, on the exact date in which they themselves attain the age of 16.

Since the Education Act of 1962 up until 1997, compulsory schooling legislation allowed children born between $1^{\text {st }}$ September and $31^{\text {st }}$ January to leave school at the beginning of the Easter holiday of the school year in which they attained the prevailing compulsory schooling age. However, those in the same class (or school year cohort) born between $1^{\text {st }}$ February and $31^{\text {st }}$ August were not considered to have attained the compulsory schooling age until the last week of May, shortly before the end of the summer term, typically in May/June (see Appendix 1). ${ }^{4}$

Entry rules in England and Wales determine that an age group or class consists of children born between the first day of September and the last day of August in the following year. The typical school entry date is September, although this has changed

\footnotetext{
3 These changes in the school leaving age have been used in the literature to identify the effects of schooling on earnings (Harmon and Walker, 1995; Chevalier, Walker and Zhu, 2003), children's education (Chevalier, 2004) and citizenship (Milligan et al., 2003), amo ng others.

${ }^{4}$ The previous Education Act of 1944 established the end of the term in which an individual attained the age of compulsory schooling as the minimum school leaving date.
} 
recently and considerable autonomy has been given to Local Education Authorities as to how to implement the commencement of compulsory, primary schooling regarding issues such as entry deferment, etc., which is more of an exception than a possibility.

The distinction in school leaving dates by date of birth within the same class creates an important discontinuity in educational attainment not only because it implies a nominal difference of two to three months of schooling, but also because the qualification system in England and Wales faces students with crucial intermediatelevel examinations at the end of the summer term. The relationship between date of birth, age rank in the classroom and possible school leaving dates is exemplified in Table 1. Legal school leaving dates show a discontinuity in August-September and January-February. Since entry date induces a discontinuity in relative age/maturity for August-September, this is not a reliable source of identification of the effect of additional compulsory schooling on the outcomes of interest. Instead, the JanuaryFebruary comparison presents a single type of discontinuity which we fully exploit in this paper.

Students who are forced to stay on in school until a later date have higher incentives to take examinations as much of the work at school in those final months of the school year is geared towards the final examination. The outcome of these exams is well known to provide strong signals for employers about the skills and preparation of the individuals who attain a given level. The economic returns to these qualifications have been documented by Dearden (1999) and Blundell et al. (2003).

Many $20^{\text {th }}$ Century reforms to the UK education system have been designed to widen access and improve the performance of pupils at the lower end of the attainment distribution, in an attempt to reform what has historically been a rather elitist system. The previously discussed reforms raising the length of compulsory schooling can be interpreted in this context. ${ }^{5}$ In the 1980 s, another quite distinctive feature of the

\footnotetext{
${ }^{5}$ During the 1960s and 1970s, secondary schools in England and Wales underwent a period of radical change, in a further attempt to widen access. Prior to this period, students of differing abilities were sent to different types of school, receiving very different types of education. "Clever" students (i.e. the top 10-20\%) were sent to elite schools called grammar schools. These students were also most likely to go on to higher education (HE). Over the 1960s this selective system was progressively phased out in favour of a comprehensive one, although certain schools can still select their intake on the basis of ability.
} 
English and Welsh education systems was also subject to a major reform, namely the change in the system of national public examinations. Since the 1950s, secondary school students who were academically inclined (grammar students) took Ordinary Level (age 16) and Advanced Level (age 18) examinations. ${ }^{6}$ O-levels and Alevels were an essential requirement to enter higher education. Less academically oriented pupils could take the Certificate of Secondary Education (CSE) at 16 before they left school. In 1988 the O level and CSE exams were combined in the GCSE (General Certificate of Secondary Education), still taken at age 16. This change also marked a turning point in the achievement of 16 year olds in the UK, implying a uniform examination instead of choosing whether to go for the lower level CSE option or the more difficult $\mathrm{O}$ level examination. This may have encouraged those who were academically on the borderline between CSE and O level to aim for a higher level of attainment. As Vignoles and Hansen (forthcoming) argue, GCSEs have proved more accessible than $\mathrm{O}$ levels and considerably more students now leave school with at least some qualifications.

In addition to the "academic" path of qualification attainment, traditionally characterised by central government determining the content and assessment of qualifications along a route that has clearly defined targets and requirements for progression to the next level, the alternative "vocational" route has a more disparate structure of training provision, with the government traditionally allowing private (and multiple) institutions greater freedom in determining the content and assessment of vocational qualifications.

The result of this historical provision of post 16 qualifications has been that, upon reaching the minimum school leaving age, individuals who wish to continue their education are faced with an unambiguous choice. The options are either to continue along the academic route and obtain GCE "A" levels with the possibility of go ing to a higher education institution or undertake a vocational qualification in the hope that the qualification provides the necessary skills that prepare the individual for a job in a particular firm or sector of the economy. Amongst other things, we will show that changes in features of compulsory schooling have been biased towards the path of

\footnotetext{
${ }^{6}$ These are national public examinations marked by independent assessors.
} 
academic attainment rather than being neutral.

\subsection{Date of birth effects on educational attainment}

\section{The data}

We use data from the Quarterly Labour Force Survey (LFS) over the 1993-2003 period, which allows us to get comparable measures of academic and vocational educational attainment. The LFS is a quarterly sample survey of households living at private addresses in Great Britain. Each quarter interviews are achieved at about 59,000 addresses with about 138,000 respondents. A core of questions covering household, family structure, basic housing information and demographic details of individuals in the households is included in every survey, together with non-core questions which vary from quarter to quarter. The LFS is based on a systematic random sample design which makes it representative of the whole of Great Britain. Each quarter is made up of 5 "waves", each of approximately 12,000 households. Each wave is interviewed in 5 successive quarters, such that in any one quarter, one wave will be receiving their first interview, one wave their second, and so on, with one wave receiving their fifth and final interview. ${ }^{7}$

Crucially for our purposes, the LFS provides information on the exact month and year of birth of individuals in our sample, together with information on their level of academic and vocational attainment. Unfortunately, there is no background information on characteristics such as the socioeconomic status of the individual's parents, type of school attended or even the precise region where they were brought up.

We select and pool LFS respondents aged 24 to 60, though our estimates exclude older individuals who would have been subject to the school leaving age of 15 so as to abstract from the effect of this other potential instrument. We drop individuals who arrived in Great Britain after the age of 10 , as their schooling experience would not

\footnotetext{
${ }^{7}$ For more details, see http://www.esds.ac.uk/government/lfs/.
} 
have been considerably affected by the schooling rules we analyse in this paper. We examine school leaving rules in England and Wales by looking at the sample of people resident in either of these countries, which implies some degree of noise from potential migration from Scotland or Northern Ireland into England and Wales and vice versa.

The information provided by the LFS does not allow us to infer the precise school leaving age from adults because the LFS only facilitates information on the age (in exact years) in which an individual left education. For summer born children it is legal to leave school when they are still 15 (in a period with SLA of 16) because, the individual is already legally deemed to have attained the school leaving age. Differences in this variable between summer and autumn born children would be severely contaminated as a result. We thus focus our attention on the level of educational attainment.

\section{Patterns of attainment}

Figure 1 presents the proportion of women in our sample who have attained any qualification, by date of birth. We report both the share with either an academic or vocational qualification and the share with at least an academic qualification. We have only depicted these proportions for women born in January $(\mathrm{J})$ or February $(\mathrm{F})$, in order to highlight attainment differences between these two months. A few key features emerge from this figure.

Firstly, the academic versus academic-or-vocational attainment gap considerably narrows down in 1957-1958. This is certainly due to the increase in the age of compulsory schooling, which raises the level of academic attainment partly at the expense of a lower level of vocational attainment with an overall positive effect.

Secondly, there is a marked and consistent academic attainment gap between those women born in January and February, but this is evident mainly after 1957-1958. This is no coincidence because, even though the legal distinction between January and February was in place before the RoSLA from 15 to 16, individuals compelled to stay until the summer month when the SLA was 15 were still far from reaching the bulk of 
examinations date at 16 . In other words, the SLA of 15 was equally preventing those born in January and February from improving their educational attainment, even though there would still have been a difference in the length of schooling. ${ }^{8}$ Quite plausibly too, the advantage of February-born children appears too be starker in the years immediately following the RoSLA, which is basically when then the school leaving age rules would have been more binding. As attainment improves over time, the proportion of people compelled to gain a qualification as a result of the rules would tend to diminish.

The situation for men over the same period is not dissimilar. We can observe that men are more likely to attain a qualification through the vocational route over the full period, which is consistent with the job-oriented type of qualifications on offer. A lot of the improvement is mostly explained by rising academic attainment, particularly through the RoSLA reform, which also appears to activate a previously dormant separation between January and February-born men. This attainment gap appears to be more moderate in size than for women and particularly strong in the years immediately after RoSLA.

In figures 3 and 4 we briefly examine the existence of a January-February gap at higher levels of academic attainment for women and men, respectively. We can observe how the January-February gap is concentrated at the lowest level of attainment, with some small positive effects for women at level 2, which is also achieved by age 16 . This suggests that compulsory schooling rules compel individuals at the lower end of the ability distribution to stay on for a few months and leave school with an academic certification, rather than compel high ability individuals to stay on and then get the high academic grades. ${ }^{9}$ Figures 3 and 4 also indicate a rise in attainment at levels 3 (A-levels) and 4 (degree) for those born after 1971, which

\footnotetext{
${ }^{8}$ This would be consistent with Pischke (2004), who finds little evidence of the effect of a reduction in the length of the schooling for German individuals following a series of state-level reforms which were implemented to bring uniformity in the school year across German laender or states.

${ }_{9}$ Interestingly the RoSLA reform has a strong impact on both levels 1 and 2 for men and women, though there is no significant spillover effect on individuals with higher levels of attainment as one would predict if medium ability/middle class individuals were expected to incur extra schooling in order to keep the distance with their immediate competitors. Chevalier et al. (2003) have interpreted this as evidence of a relatively small value of signalling in education, though it could be the case that individuals can still distinguish from each other using more detailed grade information than available to the econometrician.
} 
coincides with the previously discussed changes in the examinations at age 16 and also with a period of expansion (supply) in further and higher education.

We then focus on the attainment discontinuities caused by school entry and exit rules by plotting the difference in attainment (probability of obtaining an academic qualification) between individuals born in February versus January on one side and those born in September versus August on the other. In Figure 5, we present such differences for women Most remarkable is the massive attainment growth between August and September 1957, explained by the school entry-assignment to the first school year affected by RoSLA. The high incidence of positive dark bars to the right of that point reflects the role of the Easter-leaving rule, which tends to fade as time passes by. Prior to 1957, light-coloured bars representing the September-August difference are of considerable size and positive, suggesting that being the oldest in the class had an overall positive impact on attainment. Following RoSLA, those who are the youngest in their class are compelled to stay until the exams' date, and hence are observed to outperform those born immediately afterwards, i.e. in September. A very similar pattern is also reproduced by men, as shown in figure 6 , although in the latter case, the distinction in the January-February gaps pre and post RoSLA is less clear cut.

\subsection{Significance of the results and robustness checks}

A simple way to test the effect of the schooling exit rules is to compare the January versus February attainment gap across groups of individuals that differ in their exposure to this rule. One such possible approach is to establish comparisons between England and Wales on the one side and Scotland on the other. Scotland has a fairly different educational system but comparisons between levels of educational attainment are far more common given the degree of labour mobility within Great Britain. An important aspect of these differences is the fact that school leaving rules in Scotland establish no different rules for individuals born in January and February, 
thus providing with another possible test (difference in differences) of the role of compulsory schooling rules in shaping the January-February gap. ${ }^{10}$

In Panel A of Table 2 we present the sample probabilities of attaining an academic qualification for men and women born in January and February. We choose to concentrate on the post-RoSLA period (cohorts born in 1957/58 and after) in order to draw conclusions from a fairly homogeneous period as far as compulsory schooling regulations are concerned. For both genders, the gap between February and January is positive and significant in England and Wales, whereas this is not the case for Scotland. The cross-country difference in differences suggests a four percent extra probability of attaining a qualification as a result of compulsory schooling exit rules, irrespective of gender.

A possible robustness check is to compare two months for which we are aware of no discontinuity induced by entry or exit rules in either England and Wales or Scotland. In Panel B we compare attainment in May and April and find no statistically significant differences, confirming that our estimates genuinely capture the effect of compulsory schooling rules.

In Table 3, we present estimates from a linear model of the probability of attaining an academic qualification for individuals in school cohorts 1957 to 1974 . We control for region of residence, ethnicity, date at survey time (because some people obtain their highest qualification when adult) and year of birth (in order to capture trends in educational attainment). We also show a specification that excludes region and ethnicity to check the robustness of the estimated effect and, indirectly, the reliability of the instrument's independence. In panel A we control for quarter of birth, keeping those born September to November (quarter I) as the baseline reference group. Column 1 for women suggests a higher level of attainment for individuals born in the

\footnotetext{
${ }^{10}$ Given the evidence on Scotland's rules we have gathered so far, class composition in Scotland is determined in most cases by children born March to February the year after. This however is not such a clear cut separation as in England and Wales for our period of analysis because there is a degree of discretion across Local Education Authorities as to which dates of birth (months leading to February) grant parents the right to defer entry into primary school. Regarding school leaving at 16, Scotland provides a different exit rule discontinuity, whereby people born March to August must stay until the end of the summer term, whereas those born before the end of February must come back to school afterwards for the Fall term, being allowed to drop out at Christmas. No relevant examinations appear to take place during the Fall term.
} 
Spring and Summer months. However, as column 2 shows, when we include a dummy for whether the individuals were entitled to leave school by Easter (i.e. born September to January), this effect is reversed. The Easter leaving entitlement effect is identified in this specification because within quarter II some individuals (i.e. born December and January) are allowed to leave by Easter whereas those born in February must wait longer. The equivalent estimate in column (3), which excludes some of the controls, suggests a nearly identical effect of the Easter leaving rule. This reversal in the effect of "being the youngest in the class" is also found for men, and is perhaps easier to notice looking at the specification in Panel B. Here, instead of controlling for quarter of birth, we include a linear term in the age rank of the individual within his/her class peers. A rank of 1 implies being the oldest in the group, whereas the individual ranked 12 is the youngest. Estimates in columns 1 and 4 suggest younger people enjoy an advantage, but inclusion of the Easter leaving dummy (columns 2 and 4 for women and men respectively) reverses this coefficient, which now becomes negative and significant. The same applies when including a square polynomial term on age rank, with results displayed in Panel C. Notice that, under this last specification, we have to reject the hypothesis that relative maturity within school cohort plays no role on the educational outcome, even accounting for the school leaving date effect.

\section{Estimates by month of birth}

It is helpful to examine the estimated coefficients for a set of month dummies in a similar type of specification. Figure 7 (Figure 8) presents these values for women (men) with their confidence intervals, keeping January as the baseline comparison group. The January-February discontinuity is clearly observed, but what is also interesting is the declining path of attainment away from the discontinuity point, particularly after February. This suggests that, were it not for the school exit rules, September born individuals would experience a better level of attainment, presumably as a result of the maturity effect which is partly dismissed by Angrist and Krueger (1991). Our previous figures suggest this was indeed the case prior to the RoSLA reform, that is, before the January-February rule had an effective "bite". It is thus precipitate to argue that age rank measures can be confidently treated as exclusion restrictions. 
We performed a final robustness check to address the importance of the JanuaryFebruary school leaving rule. Policy changes provide us once more with a natural experiment, with legislation passed in 1997 leading to a single school leaving date set by the incoming Labour government of Tony Blair. In a Circular number 11/97, the Secretary of State for Education used legislation enacted in the 1996 Education Act to set up a common school leaving date coinciding with the end of the main examination period (see Appendix 1). This meant that students in the school year 1996-1997 where the last to face a January-February discontinuity in school leaving dates. We use data from specially requested tabulations from the Youth Cohort Study of England and Wales (YCS), a programme of longitudinal research designed to monitor the behaviour and decisions of representative samples of young people aged sixteen upwards as they make the transition from compulsory education to further or higher education, or to the labour market. We use information from sweep one of cohorts 8 (those eligible to leave school in 1995-96), 9 (eligible to leave school in 1996-97) and 10 (eligible to leave school in 1998-99). This means that we can effectively compare staying on behaviour of students before and after the dualschool leaving date system was transformed into a system with a single leaving date.

Given that the sample of those who report their labour market status is approximately about 12,000 individuals per year, we compare the average probability of staying on for individuals born September to January against those born February to June. We report these differences for the month of April (following Easter) in Table 4, showing a two percentage point gap for the younger group relative to the older prior to the reform. This gap disappears in the post-reform year of 1999 (YCS cohort 10), with difference in differences across years providing results at the borderline of 5 percent significance level. ${ }^{11}$

\footnotetext{
${ }^{11}$ Results for May and different grouping by date of birth provide similar results. There is considerable non-response to this section of the questionnaire and results should be treated with caution. The alternative strategy of looking at the staying on behaviour of individuals in the LFS was not feas ible because data refers to a full quarter which does not allow us to identify the actual behaviour in the relevant months of April and May following the Easter leaving date.
} 


\section{The employment effects of schooling in England and Wales}

Following Angrist and Krueger (1991), we ask the question of whether observed differences in educational attainment by month of birth are somehow translated into more permanent, labour market effects. Unlike them, we are in a position to test their implicit assumption that relative age rank can be adequately excluded from a second stage regression. Unfortunately, the LFS is not dense enough to provide us with meaningful numbers of individuals for whom wages are available with which to carry this type of estimation. ${ }^{12}$ We focus instead on the labour market status of individuals in our sample, with particular attention to their employment probabilities. In labour markets affected by frictions and rigidities, there is genuine interest as to how enhancing people skills can improve their labour market prospects by making them more employable and more willing to participate in the labour market in the first place. From this point of view, it is valid to ask whether compulsory schooling rules are an effective substitute or a more efficient incentive than welfare-to-work policies or adult-training programmes. Our interest in the effects of schooling on employment is also motivated by the pattern of increasing participation of females in education and in the labour market, which appears to suggest a steeper association between educational attainment on the one hand and employment and earnings on the other.

Before moving to the estimation of the causal impact of attainment on labour market outcomes, we first report the observed association between month of birth and activity and employment rates. Figure 9 displays aggregates of both rates for women over our sample period (1993-2003) by date of birth (1948-1974). The observed pattern suggests a systematically higher probability of being active and in employment for women in February relative to January after 1957. With a pooled sample such as ours, the figure masks improvements in participation and employment across cohorts, since both variables show a U-shaped relationship with age, reaching their lowest level at the usual time of childbearing. It is however interesting to see that even in this aggregate picture how participation and employment rates increase for younger

\footnotetext{
${ }^{12}$ Earnings information is only extract in the first and fifth (last) quarters from every individual, there is a high and unreliable level of imputation and self-employed individuals do not report earnings.
} 
cohorts. The pattern for men, depicted in Figure 10, is equally suggestive of a positive employment and participation effect of February versus January following RoSLA. ${ }^{13}$

The crude differences in participation and employment probabilities for those born in January and February are reported in Table 5. Estimates for men suggest a "reduced form" impact of slightly more than half a percentage point for both activity and employment. As for women, estimates are found to be 0.4 percent for activity and 0.7 percent for employment. A fairly simple Wald Estimate of the effect of attainment on these labour market outcomes can be derived by dividing the reduced form estimates on the estimated difference in qualification attainment probability, taken from Table 2. This implies an increased probability of being active and employed for both women and men as a result of gaining an academic qualification.

\section{Estimation framework}

The logical next step is to proceed with instrumental variable estimates of the effect of academic attainment on these outcomes. Angrist and Krueger estimate a two equation model of the following type:

$$
\begin{gathered}
s_{i}=X_{i} \pi+\sum_{c} Y_{i c} \delta_{c}+\sum_{c} \sum_{j} Y_{i c} Q_{i j} \theta_{j c}+\varepsilon_{i}, \\
p_{i}=X_{i} \beta+\sum_{c} Y_{i c} \xi_{c}+\rho \cdot s_{i}+\mu_{i},
\end{gathered}
$$

where $s_{i}$ is individual $i$ 's educational attainment, $X_{i}$ is a vector of covariates, $Y_{i c}$ is a vector of dummies for whether individual $i$ was born in year $c$ and $Q_{i j}$ is a set of dummies indicating whether the individual was born in a particular quarter $j=2,3,4$. Equation (4.2) describes the behaviour of an outcome variable $p_{i}$ as a function of schooling $s_{i}$, the vector of covariates and the year or cohort of birth.

\footnotetext{
13 The slight dip in employment around the 1970 cohort is explained by the higher level of unemployment experienced by these cohorts when they entered the labour market during the early 1990s recession.
} 
Since we have information on the precise month of birth, we can predict schooling more accurately with a finer set of month dummies $\widehat{Q}_{i k}$, with $k=2 \ldots 12$.

$$
s_{i}=X_{i} \pi+\sum_{c} Y_{i c} \delta_{c}+\sum_{c} \sum_{k} Y_{i c} \widehat{Q}_{i k} \hat{\theta}_{k c}+\varepsilon_{i}
$$

It is still possible to identify the impact of schooling on the outcome whilst controlling for the quarter of birth in the outcome equation because there is variation in the schooling levels within the particular quarter according to whether the individual was born before or after the $31^{\text {st }}$ January threshold. If we consider a year to be defined as the set of months corresponding to students in a specific school year, that is, a class (from September (1) to August (12)), the second quarter (December, January, February) can be split into two groups according to the compulsory schooling discontinuity, i.e. December and January versus February. Hence it is this withinquarter variation that identifies the effect of schooling.

$$
p_{i}=X_{i} \beta+\sum_{c} Y_{i c} \xi_{c}+\sum_{c} \sum_{j} Y_{i c} Q_{i j} \lambda_{j c}+\rho \cdot s_{i}+\mu_{i}
$$

Quarter of birth effects in equation (4.4) allow for a direct impact of an individual's age rank within its peer cohort on the outcome of interest. Maturity, physical development and other age-related characteristics may well affect labour market outcomes through ways other than schooling. Failure to account for this can lead to biased estimates, with the sign of the bias being negative if people born in the last quarter are more likely to have a worse labour market performance for these unobserved reasons. Furthermore, the positive impact of compulsory schooling for younger individuals that should be found in the first stage will be considerably attenuated by the negative age effect. This will considerably weaken the link between the instrument and the school attainment, implying undesirable finite sample biases.

\section{Estimation results}

We present in Table 6 a summary of information relative to the first stage of our estimation strategy. Based on the results of a regression of attainment on survey date 
dummies, region and ethnicity indicators, together with age groups (school year) and month of birth interactions, we test the significance of the difference between the February and January coefficients. We report separately the test results for the baseline difference (based on the first age group after RoSLA) and those for the joint test for the differences in all years. For women, the respective F-test values are 5.79 and 4.09, whereas for men the weak instrument problem appears to be more of an issue with values of 10.30 and 1.70. It is important to note that these are lower-bound values of the relevant F-statistics since it is possible to assume some structure on the way that age rank affects outcomes and open up the discontinuity "window". We therefore report the test results for a comparison of the average of the two birth months prior before the discontinuity (potential Easter-leavers) and two months afterwards too. In that case the F-statistics are considerably enhanced, though results should be taken with caution because the first stage results could still be too weak.

We now move to discuss the estimates of the impact of schooling on labour market outcomes. In Table 7 we report results for women, comparing OLS and Two-Stage Least Squares estimates for each specification (with or without region and ethnicity dummies) and by gender. All specifications include a polynomial of age rank in school cohort interacted with school cohort. ${ }^{14}$ These maturity effect controls are statistically significant in all cases, with the exception of the models describing male participation. On the other hand, the inclusion of regional and ethnicity dummies does not appear to have any effect on either the OLS or TSLS estimates.

Starting with women, the effect of a qualification on the probability of participation goes down from the OLS estimate of 0.24 to the TSLS of 0.21. Assuming independence, these estimates are not different in a statistically significant way. We find the same pattern for the employment probability, going from the OLS estimate of 0.26 to the TSLS one of 0.22 . Overall, OLS only appears to slightly overestimate the true effect of an academic qualification.

The situation for men is slightly different. In terms of participation in the labour market, both OLS and TSLS estimates are considerably lower, around 0.08 , reflecting 
the almost complete participation in this sample of prime-age men. This is also the only instance in which relative age effects do not seem to have any independent impact at all. The picture is quite different regarding the probability of employment, with TSLS estimates (around 0.21) exceeding OLS (0.16). This difference may well not be entirely significant but suggests a completely different pattern than that found for women.

\section{Heterogeneity in the effect of qualification attainment}

The interpretation of IV estimates is of key interest in a subject such as this in which research is likely to inform policy makers' decisions. Under fairly general conditions, it is well known that IV estimates the effect of the treatment on a given outcome for the subpopulation of treated individuals whose treatment (education in our case) can be influenced by the instrument (the combination of date of birth with school leaving rules). School leaving rules are unlikely to have the same impact across all the population of students, which is confirmed by the fact that date of birth has little impact on the probability of attaining high-level qualifications.

When there is heterogeneity of treatment effects of qualification attainment, the question arises as to how representative the derived IV estimate can be of the treatment effects for a population of interest, given the very local nature of IV. We decided to investigate the existence of any patterns of variation in our IV estimates across our few available controls (school cohort and period surveyed) and explore the implications of treatment effect heterogeneity by unobservable characteristics.

In Table 8 we present estimates of the effect of obtaining an academic qualification on labour market participation and employment status for separate cohort and survey date groups. The first stage of the IV estimates regresses the qualification variable on a full set of interactions of month of birth, cohort of birth and LFS survey quarter and year. ${ }^{15}$ In the second stage we control for interactions of survey date (quarterly

\footnotetext{
${ }^{14}$ We did also estimate the model with quarter dummies interacted with school cohort, though the square polynomial always appeared to explain the data better than the quarter-based model.

${ }^{15}$ We used this specification to describe attainment probabilities because it is the most complete, although a the joint significance test of the interactions between birth date and LFS survey date, could not reject additivity. These interactions are supposed to capture whether an individual born in a
} 
precision) and school cohort year, in addition to a square polynomial of relative maturity interacted with cohort.

Our OLS estimates of the participation probability for women indicate that the effect of qualification attainment was higher for more recent cohorts and slightly declined over the sample period. For example, the impact for women born 1957-1962 in 20012003 (in their early forties) was 19 percentage points whereas for women born 19691974 this was as high as 35 percent in the 1993-1996 period (in their mid-twenties). TSLS estimates are relatively similar, with the biggest discrepancy found for those born 1963-1968 in 2001-2003, for whom the TSLS estimate is 0.16, compared with the OLS of 0.22 . The declining effect of education with survey time across cohorts identifies an age-related variation that can be partly explained by the association between education and childrearing, with more educated women being more likely to postpone spells outside the labour market. However, according to TSLS estimates, this phenomenon is no longer relevant for the youngest cohort considered in our estimates. Employment probability estimates for women largely mirror the findings for participation probability. The declining effect of education on employment for women in the 1963-1968 cohort is again quite marked according to TSLS estimates, ranging from 33 percent in 1993-1996 to 17 percent in 2001-2003.

Turning now to men, OLS estimates of participation probability are rather stable across cohorts whilst slightly increasing with date of survey. IV estimates only confirm this point for the oldest cohort in the sample, which is consistent with the way education increases individual attachment to the labour market as they age, although individuals in our sample are on the young extreme of the age group affected by the recent trend of declining participation for older low skilled men. For the younger cohorts in our sample, IV cannot reject equality of effects within cohort.

Regarding the effects of qualification attainment on the probability of employment, TSLS are similar or higher than OLS estimates. The TSLS effect of attainment on employment (29 percent) in 1993-1996 for the youngest cohort (1969-1974) is high and emphasizes the role of education in periods of economic downturn for young 
people. This effect goes down with age to 21 percent in 2001-2003 for the same cohort, but is still above that for any other cohort. OLS estimates do also suggest that an academic qualification has become more important in terms of employment for the more recent cohort.

We further investigate heterogeneity patterns on unobserved characteristics, which unfortunately account for a large part of the variance in education and outcomes. In our context with a binary instrument and a binary education treatment there are in principle four possible ways of classifying individuals according to their response to the policy: (1) individuals who obtain a qualification independently of their policy status (i.e. always educated); (2) individuals who never obtain a qualification (never educated); (3) individuals who do not obtain a qualification if allowed to leave school by Easter but who obtain one if compelled to stay on and (4) those who behave the exact opposite way. It is reasonable to assume that group (4) is empty, so that being compelled to stay on longer never drives anyone in the population to get less education than they would have done otherwise. One way to model this monotonic impact of school leaving rules on attainment is a latent index model, whereby individuals' propensity to obtain a qualification is summarized by a single unobserved index $\varepsilon_{i}$.

$$
S_{i}=\mathbf{1}\left(\gamma_{0}+\gamma_{1} Z_{i}+\varepsilon_{i}>0\right)
$$

The binary instrument $\mathrm{Z}$ separates the full range of propensity values into the above named groups (1) to (3), according to whether they were compelled by school leaving rules to stay on at school beyond Easter. Expected potential gains from obtaining a qualification can indeed vary with values of this index. Otherwise, IV would estimate the Average Treatment Effect (ATE) in the population. Under heterogeneity, IV identifies an average of Marginal Treatment Effects (MTEs) for each index value within the subgroup (3), commonly known as "compliers" - i.e. those whose behaviour is changed by the school leaving rules. This is indeed a Local Average Treatment Effect (LATE), and will not necessarily capture ATE or other treatment effects of interest on a wider population than that made out of compliers. 
With potential outcomes with and without an academic qualification defined as $P_{1 i}=\rho_{1}+u_{1 i}$ and $P_{0 i}=\rho_{0}+u_{0 i}$, respectively, a simple way to model this variability is to assume that idiosyncratic treatment effects are jointly normally distributed with the attainment propensity index $\varepsilon_{i}$. In that case, a single covariance coefficient captures the relationship between the unobserved error and the unobserved propensity index, with $E\left[u_{1 i} \mid \varepsilon_{i}\right]=\sigma_{1} \cdot \varepsilon_{1 i}$ and $E\left[u_{0 i} \mid \varepsilon_{i}\right]=\sigma_{0} \cdot \varepsilon_{0 i} \cdot{ }^{16}$ This implies that:

$$
E\left[P_{1 i}-P_{0 i} \mid \varepsilon_{i}\right]=\left(\rho_{1}-\rho_{0}\right)+\left(\sigma_{1}-\sigma_{0}\right) \cdot \varepsilon_{i},
$$

which shows a linear relationship between the marginal treatment effect and the individual propensity to obtain a qualification. A positive $\left(\sigma_{1}-\sigma_{0}\right)$ term indicates selection based on potential gains, whilst the opposite may occur if those who are more likely to benefit from the treatment are actually the most constrained into it.

Since we do identify expected outcomes by treatment and instrument status, these four moments just identify the four parameters in our model. Take those individuals with an academic qualification, for example, the intercept $\rho_{1}$ and the correlation term $\sigma_{1}$ are identified from the intercept and coefficient of a regression of the outcome variable on the correction term (varies with $\mathrm{Z}$ ) that captures the expected value of the propensity to receive the treatment, using the distributional assumption to calculate its value. ${ }^{17}$ The same procedure applies to the sample of individuals who do not obtain a qualification, adjusting for the fact that expected propensity for qualification attainment in this group is different.

\footnotetext{
${ }^{16}$ With a binary outcome, the $u$ terms cannot be normally distributed. Specifying the outcome model as a probit model would involve estimating a mixture model in which we should integrate a non-linear function. The estimation of such a model is beyond the aim of this paper.

${ }^{17}$ That is, the model states that

$E\left[P_{i} \mid S_{i}=1, Z_{i}\right]=\rho_{1}+\sigma_{1} E\left[\varepsilon_{i} \mid \varepsilon_{i}<-\gamma_{0}-\gamma_{1} Z_{i}\right]=\rho_{1}+\sigma_{1} \phi\left(\gamma_{0}+\gamma_{1} Z_{i}\right) / \Phi\left(\gamma_{0}+\gamma_{1} Z_{i}\right)$ and $E\left[P_{i} \mid S_{i}=0, Z_{i}\right]=\rho_{0}+\sigma_{0} E\left[\varepsilon_{i} \mid \varepsilon_{i} \geq-\gamma_{0}-\gamma_{1} Z_{i}\right]=\rho_{0}-\sigma_{0} \phi\left(\gamma_{0}+\gamma_{1} Z_{i}\right) /\left[1-\Phi\left(\gamma_{0}+\gamma_{1} Z_{i}\right)\right]$, where $\phi$ and $\Phi$ denote the normal density and cumulative distribution functions. Consistent estimates can be obtained by substitution with estimated values for $\gamma_{0}$ and $\gamma_{1}$ from a first-stage probit estimation of (4.5).
} 
In Table 9 we compare different estimates of the effect of qualification attainment on the probabilities of being active and employed in the labour market. We do this by gender for the full sample of individuals and the subsample of those who do not attain a post-16 academic qualification, thereby excluding people with A-levels or degrees. ${ }^{18}$

A marginal treatment effect (MTE) is defined by the model as the impact of the treatment for a particular value of the education propensity index, namely: $\operatorname{MTE}\left(\varepsilon_{i}\right)=\left(\hat{\rho}_{1}-\hat{\rho}_{0}\right)+\left(\hat{\sigma}_{1}-\hat{\sigma}_{0}\right) \varepsilon_{i}$. We first report the estimated treatment effect for individuals at the margin between "never-educated" and "compliers". According to the single index model, this simply evaluates the treatment effect at the point $\varepsilon_{i}=-\gamma_{0}-\gamma_{1} \equiv \varepsilon_{N_{-} C}$. We also estimate the treatment effect at the margin between compliers and always educated, which implies the higher propensity value of $\varepsilon_{i}=-\gamma_{0} \equiv \varepsilon_{C_{-} A}$. In between these estimates, we report IV which, as we said, is the LATE for values such that $-\gamma_{0}-\gamma_{1}<\varepsilon_{i}<-\gamma_{0}$. OLS estimates are provided for comparison too.

In both samples, there is a considerable majority of "always educated" individuals, with "compliers" being a fairly small fraction of the total. Can IV estimates be reliably extrapolated from this small subset? ATE estimates, for example, extrapolate the treatment effects from the points at which treatments are identified using the normality assumption.

Starting with the full sample of women, both participation and employment estimated treatment effects are estimated to be lower than OLS. Comparison between effects at both margins suggests a slightly declining pattern with propensity to get a qualification. Given that the margins are located at the far left of the propensity distribution, estimated ATE is well below whilst IV/LATE clearly lies between the MTEs, at 9.6 percent for participation and 12.8 percent for employment. Considering the smaller sample of women with no post-16 qualifications, all effects are found to be lower than in the full sample but the qualitative picture is identical. This finding

\footnotetext{
${ }^{18}$ In order to abstract from maturity effects whilst achieving a sufficiently large sample, we took the sample of individuals born in a six-month window around the date of birth that marks the school leaving age discontinuity (November to April).
} 
might be due to the fact that the "any qualification-treatment" is a composite of treatments, and that our instrument has some limited power into compelling individuals into the higher le vels of this treatment.

The effects of qualification attainment for men on activity are found to exceed OLS estimates. This was not the case in our basic estimates but did indeed occur for some cohort/time groups in Table 8. It is certainly difficult to understand what may drive participation for prime aged males and the relative variability of our estimates appears to suggest some degree of caution. Taking these results at face value, the participation effects seem to increase with treatment propensity, thereby extrapolating an ATE of 21 percent from the LATE of 15 percent. Point IV estimates of the employment effects (27 percent) are also higher than OLS (16 percent). In this case, the profile looks fairly flat, if not increasing, suggesting little variation with the propensity to become educated. Restricting the sample to men with no "post-16" qualifications leads to very similar estimates, confirming the previous uniformity result.

\section{Conclusions}

This paper has shed new light on the way compulsory schooling improves the educational attainment of individuals and how it has a lasting impact on individual's performance in the labour market. We used a natural experiment stemming from institutional features of the education system in England and Wales that established different school leaving dates for individuals within the same broad age group or cohort. With an age-group or cohort defined by entry rules as those individuals born between September and the following August, those born prior to the end of January were deemed to have attained the compulsory school leaving age by Easter, whereas their younger peers had to stay in school until the Summer school leaving date in May. We showed that this rule had a stronger impact on attainment differences in the years following the raising of the school leaving age, in effect for the first time for the 1957-1958 cohort. Given the structure of the examination system, we argue that the key effect of the policy is not really increasing the length of schooling for the younger group in a class, but to compel them to reach the stage in which they can take exams and leave school with a credential. 
This natural experiment allows us to identify the pure effect of compulsory schooling, netted out of relative age effects that contaminate estimates based on date of birth when, as for most of the US, individuals can drop out on the exact birthday in which they attain the school leaving age and variation in compulsory schooling comes from school entry rules. We argued that such school entry rules will lead to underestimates of the true effect of compulsion because they induce a discontinuity in the relative age of an individual with respect to her peers. Relative maturity has been discussed in the literature as a non-negligible advantage and we show that it has indeed a positive, independent effect on attainment.

We use differences in the school leaving rules between England and Wales on one side and Scotland on the other to check the robustness of our results. Our findings are also strengthened by the comparison of the January-February attainment gap before and after the Easter school leaving date was finally removed by the incoming Labour government in 1997/1998.

We did also address the question of whether school leaving rules have had a significant impact on the labour market performance of men and women in England and Wales. Furthermore, since we can safely assume that individuals born in the consecutive months of January and February are observationally identical in all aspects apart from the possible school leaving dates, we can identify the causal employment and participation effect of attaining a qualification. With heterogeneity of education treatment effects, we thus identify the effect of education on the "marginal" population of students who are induced to stay long enough to take examinations. Our IV estimates suggest treatment effects of a lower magnitude than those obtained through OLS, though statistically significant with the only exception of the probability of being active for prime age males. This confirms the conventional finding that education is a more important driver of employment and participation for women than it is for men. We leave for further work an analysis of features of participation (e.g. hours worked) and some of the mechanisms that can potentially explain this pattern, such as the timing of marriage and fertility behaviour.

In the light of our results, we can argue that compulsory schooling plays an important role in fostering the opportunities of low-achieving individuals, provided the 
certification system is sufficiently well tuned with the extra schooling spells. A challenge for researchers and policy makers alike is to find an answer to the question of why a policy that constrains the behaviour of individuals presumed to be utility maximisers can be as beneficial as demonstrated here.

\section{References}

Angrist, Joshua and Alan Krueger (1991). "Does compulsory school attendance affect schooling and earnings", Quarterly Journal of Economics, 106, 979-1014.

Blundell, Richard, Barbara Sianesi and Lorraine Dearden (2003). "Evaluating the impact of education on earnings in the UK: Models, methods and results from the NCDS", IFS Working Paper W03/20, London.

Bound, John, David Jaeger and Regina Baker (1995). "Problems with instrumental variables when the correlation between the instruments and the endogenous explanatory variable is weak", Journal of the American Statistical Association, 90, 443-450.

Bound, John and David Jaeger (1996). "On the validity of season of birth as an instrument in wage equations: A comment on Angrist and Krueger's 'Does compulsory school attend affect schooling and earnings?"”, NBER working paper n. 5835, Cambridge, MA.

Chesher, Andrew (2003). "Nonparametric identification under discrete variation," CEMMAP Working Paper CWP19/03, London.

Chevalier, Arnaud (2004). "Parental education and child's education: A natural experiment", mimeo, University College Dublin.

Chevalier, Arnaud, Colm Harmon, Ian Walker and Yu Zhu (2003). "Does education raise productivity?", University College Dublin Working Paper, ISSC, WP2003/01, Dublin.

Dearden, Lorraine (1999). "The effects of families and ability on men's education and earnings in Britain", Labour Economics, 6, 551-567.

Dudink, Ad (1994). "Birth date and sporting success", Nature, 368, 592.

Harmon, Colm and Ian Walker (1999). "Economic return to schooling for the UK", American Economic Review, 85, 1278-1286. 
Milligan, Kevin, Enrico Moretti and Philip Oreopoulos (2003). "Does education improve citizenship? Evidence from the U.S. and the U.K.", NBER Working Paper n. 9584, Cambridge, MA.

Plug, Erik (2001). "Season of birth, schooling and earnings", Journal of Economic Psychology, 22, 641-660.

Pischke, Jorn Steffen (2004). "The impact of the school year on student performance and earnings: evidence from the German short school years", Centre for the Economics of Education Discussion Paper n 34, London School Economics, London.

Sharp, Caroline and Pauline Benefield (1995). Research into season of birth and school achievement: A select annotated bibliography. Slough: National Foundation for Educational Research (NFER).

Strom, Bjarne (2003). "Student achievement and birthday effects", mimeo, Norwegian University of Science and Technology, Trondheim.

Vignoles, Anna and Kirstine Hansen (forthcoming). "The UK education system: an international perspective", in Machin, Stephen, Anna Vignoles and Gavan Conlon (eds.) Economics of education in the UK. 
Table 1

Example of compulsory schooling rules by month of birth in England and Wales

\begin{tabular}{lcccc}
\hline \hline Month of birth & $\begin{array}{c}\text { School } \\
\text { year } \\
\text { cohort }\end{array}$ & $\begin{array}{c}\text { Quarter } \\
\text { of birth }\end{array}$ & $\begin{array}{c}\text { Relative } \\
\text { age rank }\end{array}$ & $\begin{array}{c}\text { Allowed to } \\
\text { leave at } \\
\text { Easter }\end{array}$ \\
\hline August 1960 & $\mathbf{1 9 5 9}$ & $\mathbf{4}$ & $\mathbf{1 2}$ & No \\
September 1960 & $\mathbf{1 9 6 0}$ & $\mathbf{1}$ & 1.oldest) & Yes \\
October 1960 & 1960 & 1 & 2 & Yes \\
November 1960 & 1960 & 1 & 3 & Yes \\
December 1960 & 1960 & 2 & 4 & Yes \\
January 1961 & $\mathbf{1 9 6 0}$ & $\mathbf{2}$ & $\mathbf{5}$ & Yes \\
February 1961 & $\mathbf{1 9 6 0}$ & $\mathbf{2}$ & $\mathbf{6}$ & No \\
March 1961 & 1960 & 3 & 7 & No \\
April 1961 & 1960 & 3 & 8 & No \\
May 1961 & 1960 & 3 & 9 & No \\
June 1961 & 1960 & 4 & 10 & No \\
July 1961 & 1960 & 4 & 11 & No \\
August 1961 & $\mathbf{1 9 6 0}$ & $\mathbf{4}$ & $\mathbf{1 2}$ (youngest) & No \\
September 1961 & $\mathbf{- 1 9 6 1}$ & $\mathbf{1}$ & $\mathbf{1}$ & Yes \\
\hline \hline
\end{tabular}


Table 2

The effect of school leaving rules on the probability of attaining an academic qualification in England, Wales and Scotland

\begin{tabular}{|c|c|c|c|c|}
\hline & \multicolumn{2}{|c|}{ Women } & \multicolumn{2}{|c|}{ Men } \\
\hline & $\begin{array}{l}\text { England and } \\
\text { Wales }\end{array}$ & Scotland & $\begin{array}{c}\text { England and } \\
\text { Wales }\end{array}$ & Scotland \\
\hline \multicolumn{5}{|c|}{ Panel A - England and Wales cut-off rule: January-February } \\
\hline \multirow[t]{2}{*}{ January } & 0.7961 & 0.7138 & 0.7714 & 0.7175 \\
\hline & $(0.0018)$ & $(0.0060)$ & $(0.0020)$ & $(0.0063)$ \\
\hline \multirow[t]{2}{*}{ February } & 0.8333 & 0.7018 & 0.7933 & 0.6962 \\
\hline & $(0.0017)$ & $(0.0062)$ & $(0.0019)$ & $(0.0069)$ \\
\hline Difference & 0.0372 & -0.0120 & 0.0219 & -0.0212 \\
\hline (within country) & $(0.0025)$ & $(0.0086)$ & $(0.0028)$ & $(0.0093)$ \\
\hline Diff. in diff.s & \multicolumn{2}{|c|}{0.0492} & \multicolumn{2}{|c|}{0.0431} \\
\hline E\&W-Scotland & \multicolumn{2}{|c|}{$(0.0090)$} & \multicolumn{2}{|c|}{$(0.0097)$} \\
\hline \multicolumn{5}{|c|}{ Panel B - Robustness check (no discontinuity) } \\
\hline \multirow{2}{*}{$\begin{array}{c}\text { May-April } \\
\text { (within country } \\
\text { difference) }\end{array}$} & -0.0030 & -0.0152 & -0.0005 & -0.0128 \\
\hline & $(0.0023)$ & $(0.0081)$ & $(0.0027)$ & $(0.0087)$ \\
\hline Diff. in diff.s & \multicolumn{2}{|c|}{0.0122} & \multicolumn{2}{|c|}{0.0123} \\
\hline E\&W-Scotland & \multicolumn{2}{|c|}{$(0.0084)$} & \multicolumn{2}{|c|}{$(0.0091)$} \\
\hline
\end{tabular}

Notes: Probability of attaining any academic qualification by month of birth and country of residence. Sample sizes in each month are between 43,000 and 52,000 for England and Wales, and between 4,500 and 5,700 for Scotland. All individuals are born September 1957 to August 1974. In England and Wales the school leaving rule establishes that those born in January can drop out at Easter whereas those born in February must stay until the end of the summer term (Panel A). Panel B provides a similar comparison for a pair of consecutive months not affected by any schooling cut off rule in either of the two countries. Standard errors reported within parentheses. 
Table 3

Estimates of the effect of relative age rank and school leaving age rule on educational attainment in England and Wales

\begin{tabular}{|c|c|c|c|c|c|c|}
\hline & \multicolumn{3}{|c|}{ Women } & \multicolumn{3}{|c|}{ Men } \\
\hline & $(1)$ & $(2)$ & $(3)$ & $(4)$ & $(5)$ & $(6)$ \\
\hline \multicolumn{7}{|l|}{ Panel A - Quarter of birth } \\
\hline Born quarter II: December - February & $\begin{array}{c}0.0111 * * \\
(0.0029)\end{array}$ & $\begin{array}{c}0.0006 \\
(0.0033)\end{array}$ & $\begin{array}{c}-0.0003 \\
(0.0033)\end{array}$ & $\begin{array}{c}0.0125^{* *} \\
(0.0033)\end{array}$ & $\begin{array}{c}0.0035 \\
(0.0037)\end{array}$ & $\begin{array}{c}0.0035 \\
(0.0037)\end{array}$ \\
\hline Born quarter III: March - May & $\begin{array}{c}0.0313 * * \\
(0.0028)\end{array}$ & $\begin{array}{c}-0.0005 \\
(0.0051)\end{array}$ & $\begin{array}{c}-0.0011 \\
(0.0051)\end{array}$ & $\begin{array}{c}0.0275^{* *} \\
(0.0032)\end{array}$ & $\begin{array}{c}-0.0001 \\
(0.0057)\end{array}$ & $\begin{array}{c}-0.0003 \\
(0.0057)\end{array}$ \\
\hline Born quarter IV: June - August & $\begin{array}{l}0.0247 * * \\
(0.0029)\end{array}$ & $\begin{array}{l}-0.0071 \\
(0.0051)\end{array}$ & $\begin{array}{l}-0.0079 \\
(0.0052)\end{array}$ & $\begin{array}{l}0.0231 * * \\
(0.0032)\end{array}$ & $\begin{array}{l}-0.0045 \\
(0.0058)\end{array}$ & $\begin{array}{l}-0.0045 \\
(0.0058)\end{array}$ \\
\hline $\begin{array}{l}\text { joint significance test p-value maturity } \\
\text { Born September to January (Easter leaving date) }\end{array}$ & {$[0.0000]$} & $\begin{array}{c}{[0.0665]} \\
-0.0318 * * \\
(0.0043)\end{array}$ & $\begin{array}{c}{[0.0622]} \\
-0.0331 * * \\
(0.0043)\end{array}$ & {$[0.0000]$} & $\begin{array}{c}{[0.1846]} \\
-0.0276^{* *} \\
(0.0048)\end{array}$ & $\begin{array}{c}{[0.1946]} \\
-0.0284 * * \\
(0.0048)\end{array}$ \\
\hline \multicolumn{7}{|l|}{ Panel B - Relative age rank } \\
\hline Relative age rank within school year & $\begin{array}{l}0.0031 * * \\
(0.0003)\end{array}$ & $\begin{array}{c}-0.0014 * \\
(0.0006)\end{array}$ & $\begin{array}{c}-0.0015^{* *} \\
(0.0006)\end{array}$ & $\begin{array}{c}0.0027 * * \\
(0.0003)\end{array}$ & $\begin{array}{c}-0.0011 \\
(0.0006)\end{array}$ & $\begin{array}{c}-0.0011 \\
(0.0006)\end{array}$ \\
\hline Born Septemb er to January (Easter leaving date) & - & $\begin{array}{c}-0.0367 * * \\
(0.0039) \\
\end{array}$ & $\begin{array}{c}-0.0384 * * \\
(0.0039) \\
\end{array}$ & - & $\begin{array}{c}-0.0311 * * \\
(0.0044) \\
\end{array}$ & $\begin{array}{c}-0.0319 * * \\
(0.0044)\end{array}$ \\
\hline \multicolumn{7}{|l|}{ Panel C - Relative age rank and its square } \\
\hline Relative age rank within school year & $\begin{array}{c}0.0001 \\
(0.0017)\end{array}$ & $\begin{array}{c}-0.0002 \\
(0.0017)\end{array}$ & $\begin{array}{c}0.0001 \\
(0.0017)\end{array}$ & $\begin{array}{c}0.0085^{* *} \\
(0.0014)\end{array}$ & $\begin{array}{c}0.0018 \\
(0.0018)\end{array}$ & $\begin{array}{c}0.0015 \\
(0.0018)\end{array}$ \\
\hline Relative age rank within school year squared & $\begin{array}{c}-0.0012 \\
(0.0012)\end{array}$ & $\begin{array}{c}-0.0011 \\
(0.0013)\end{array}$ & $\begin{array}{c}-0.0012 \\
(0.0012)\end{array}$ & $\begin{array}{c}-0.0053 * * \\
(0.0013)\end{array}$ & $\begin{array}{c}-0.0023 \\
(0.0014)\end{array}$ & $\begin{array}{c}-0.0021 \\
(0.0014)\end{array}$ \\
\hline joint significance test $p$-value maturity & {$[0.0000]$} & {$[0.0266]$} & {$[0.0184]$} & {$[0.0000]$} & {$[0.0537]$} & {$[0.0687]$} \\
\hline Born September to January (Easter leaving date) & - & $\begin{array}{c}-0.0352 * * \\
(0.0043)\end{array}$ & $\begin{array}{c}-0.0371 * * \\
(0.0043)\end{array}$ & - & $\begin{array}{c}-0.0282 * * \\
(0.0047)\end{array}$ & $\begin{array}{c}-0.0292 * * \\
(0.0048)\end{array}$ \\
\hline Regional dummies & $\checkmark$ & $\checkmark$ & & $\checkmark$ & $\checkmark$ & \\
\hline Ethnic group dummies & $\checkmark$ & $\checkmark$ & & $\checkmark$ & $\checkmark$ & \\
\hline
\end{tabular}

Notes: OLS estimates fro $\mathrm{m}$ a linear probability model. Sample size: 591,836 observations (158,814 individuals) for women and 534,689 observations (147,980 individuals) for men. All individuals are born September 1957 to August 1974 . The dependent variable is a dichotomous variable which assumes value 1 if the subject has obtained an academic qualification and 0 otherwise. Huber-White heteroskedasticity robust standard errors shown within parentheses. Standard errors are adjusted in order to take into account the presence of multiple observations for each individual. The $\mathrm{p}$-value of the joint significance test on the maturity effects is shown in squared brackets. Each specification is estimated separately for men and women and always includes survey date dummies, school year dummies and an intercept. The specifications presented in columns (1), (2), (3) and (4) also include regional dummies and ethnic group dummies. Symbols: ** significant at $1 \%$ level; * significant at $5 \%$ level. 


\title{
Table 4
}

Participation in full-time education in April in England and Wales: The effects of removing the Easter school leaving date

\begin{tabular}{lccc}
\hline \hline & Pre-reform year & Pre-reform year & Post-reform year \\
& 1995 & 1997 & 1999 \\
\cline { 2 - 4 } Born September to January & 0.8252 & 0.7798 & 0.8192 \\
& $(0.0053)$ & $(0.0058)$ & $(0.0056)$ \\
Born February to June & & & \\
& 0.8482 & 0.8020 & 0.8227 \\
Difference in participation rates & $(0.0047)$ & $(0.0054)$ & $(0.0053)$ \\
& 0.0229 & & 0.0034 \\
& $(0.0071)$ & $(0.0079)$ & $(0.0077)$ \\
\hline Difference [Pre reform year]-1999 & & & \\
& 0.0195 & 0.0188 & \\
& $(0.0105)$ & $(0.0106)$ &
\end{tabular}

\begin{abstract}
Notes: Proportion of individuals participating in full-time education in April of their final year of compulsory education by month of birth. Sample sizes in each month are about 1,000 observations. Data from cohort 8 (year 1995), cohort 9 (year 1997), and cohort 10 (year 1999) of the Youth Cohort Study for England and Wales. Standard errors in parentheses. Authors' own tabulations based on specially requested tables provided by the UK Department for Education and Skills (DfES). The Easter school leaving date was last in place for the cohort of students attaining age sixteen in the 1997-1998 school year.
\end{abstract}




\section{Table 5}

The effect of the Easter school leaving age rule on participation and employment in England and Wales

\begin{tabular}{|c|c|c|c|c|}
\hline & \multicolumn{2}{|c|}{ Women } & \multicolumn{2}{|c|}{ Men } \\
\hline & $\begin{array}{l}\text { Economically } \\
\text { active } \\
\text { probability } \\
\end{array}$ & $\begin{array}{l}\text { Employment } \\
\text { probability }\end{array}$ & $\begin{array}{l}\text { Economically } \\
\text { active } \\
\text { probability } \\
\end{array}$ & $\begin{array}{l}\text { Employment } \\
\text { probability }\end{array}$ \\
\hline Born January & $\begin{array}{c}0.7617 \\
(0.0019)\end{array}$ & $\begin{array}{c}0.7166 \\
(0.0020)\end{array}$ & $\begin{array}{c}0.9412 \\
(0.0011)\end{array}$ & $\begin{array}{c}0.8805 \\
(0.0015)\end{array}$ \\
\hline Born February & $\begin{array}{c}0.7660 \\
(0.0019)\end{array}$ & $\begin{array}{c}0.7239 \\
(0.0020)\end{array}$ & $\begin{array}{l}0.9479 \\
(0.0011)\end{array}$ & $\begin{array}{c}0.8861 \\
(0.0015)\end{array}$ \\
\hline $\begin{array}{c}\text { (A) Difference in } \\
\text { labour market outcomes }\end{array}$ & $\begin{array}{c}0.0043 \\
(0.0027)\end{array}$ & $\begin{array}{c}0.0073 \\
(0.0029)\end{array}$ & $\begin{array}{c}0.0067 \\
(0.0015)\end{array}$ & $\begin{array}{c}0.0055 \\
(0.0022)\end{array}$ \\
\hline $\begin{array}{l}\text { (B) Difference in } \\
\text { the proportion attaining any } \\
\text { qualification (see Table 2) }\end{array}$ & \multicolumn{2}{|c|}{$\begin{array}{c}0.0372 \\
(0.0025)\end{array}$} & \multicolumn{2}{|c|}{$\begin{array}{c}0.0219 \\
(0.0028)\end{array}$} \\
\hline (A/B) Wald-Estimate & $\begin{array}{c}0.1156 \\
(0.0730)\end{array}$ & $\begin{array}{c}0.1962 \\
(0.0932)\end{array}$ & $\begin{array}{c}0.3059 \\
(0.0789)\end{array}$ & $\begin{array}{c}0.2511 \\
(0.1055)\end{array}$ \\
\hline
\end{tabular}

\footnotetext{
Notes: Proportions in the labour force and in employment and proportion achieving any academic qualification by month of birth. Sample of individuals born September 1957 to August 1974. Sample sizes in each month are between 43,000 and 52,000 individuals. Standard errors reported within parentheses.
} 
Table 6

F-test on the effect of the school leaving age rule on first stage regression in England and Wales

\begin{tabular}{|c|c|c|c|c|}
\hline & & d.o.f. & $\begin{array}{c}\text { F-test } \\
\text { statistic }\end{array}$ & p-value \\
\hline & & & Wome & \\
\hline \multirow{2}{*}{$H_{0}:$ February = January } & Baseline effect & 1 & 5.79 & 0.0161 \\
\hline & All school-years & $1+17$ & 4.09 & 0.0000 \\
\hline \multirow{2}{*}{$H_{0}:$ February + March $=$ January + December } & Baseline effect & 1 & 12.63 & 0.0004 \\
\hline & All school-years & $1+17$ & 6.34 & 0.0000 \\
\hline & & & Men & \\
\hline \multirow[t]{2}{*}{$H_{0}:$ February = January } & Baseline effect & 1 & 10.30 & 0.0013 \\
\hline & All school-years & $1+17$ & 1.70 & 0.0314 \\
\hline \multirow[t]{2}{*}{$H_{0}:$ February + March $=$ January + December } & Baseline effect & 1 & 19.12 & 0.0000 \\
\hline & All school-years & $1+17$ & 4.02 & 0.0000 \\
\hline
\end{tabular}

Notes: Results based on OLS estimates of a linear probability model. Sample size: 591,836 observations (158,814 individuals) for women and 534,689 observations (147,980 individuals) for men. All individuals are born September 1957 to August 1974. The dependent variable is a dichotomous variable which assumes value 1 if the subject has obtained an academic qualification and 0 otherwise. Each equation is estimated separately for men and women and includes survey dummies, regional dummies, ethnic group dummies, a full set of school year and month of birth dummies (as in equation 4.3) and an intercept. The test statistics are adjusted in order to take into account the presence of multiple observations for each individual. 
Table 7

OLS and TSLS estimates of the effect of having any academic qualifications on women's participation and employment in England and Wales

\begin{tabular}{|c|c|c|c|c|c|c|c|c|}
\hline & \multicolumn{4}{|c|}{ Women } & \multicolumn{4}{|c|}{ Men } \\
\hline & $\begin{array}{c}(1) \\
\text { OLS } \\
\end{array}$ & $\begin{array}{c}(2) \\
\text { TSLS } \\
\end{array}$ & $\begin{array}{c}(3) \\
\text { OLS } \\
\end{array}$ & $\begin{array}{c}(4) \\
\text { TSLS } \\
\end{array}$ & $\begin{array}{c}(5) \\
\text { OLS } \\
\end{array}$ & $\begin{array}{c}(6) \\
\text { TSLS }\end{array}$ & $\begin{array}{c}(7) \\
\text { OLS } \\
\end{array}$ & $\begin{array}{c}(8) \\
\text { TSLS } \\
\end{array}$ \\
\hline \multicolumn{9}{|l|}{ Participation in the labour market } \\
\hline Any academic qualification & $\begin{array}{c}0.2405 * * \\
(0.0030)\end{array}$ & $\begin{array}{c}0.2058 * * \\
(0.0637)\end{array}$ & $\begin{array}{c}0.2423 * * \\
(0.0030)\end{array}$ & $\begin{array}{c}0.2102 * * \\
(0.0622)\end{array}$ & $\begin{array}{c}0.0870^{* * *} \\
(0.0018)\end{array}$ & $\begin{array}{c}0.0762 \\
(0.0393)\end{array}$ & $\begin{array}{c}0.0892 * * \\
(0.0019)\end{array}$ & $\begin{array}{l}0.0830^{*} \\
(0.0390)\end{array}$ \\
\hline Relative age rank within school year & $\begin{array}{l}-0.0011 \\
(0.0053)\end{array}$ & $\begin{array}{l}-0.0003 \\
(0.0055)\end{array}$ & $\begin{array}{l}-0.0016 \\
(0.0053)\end{array}$ & $\begin{array}{l}-0.0008 \\
(0.0055)\end{array}$ & $\begin{array}{l}-0.0010 \\
(0.0031)\end{array}$ & $\begin{array}{l}-0.0008 \\
(0.0032)\end{array}$ & $\begin{array}{l}-0.0012 \\
(0.0031)\end{array}$ & $\begin{array}{l}-0.0011 \\
(0.0032)\end{array}$ \\
\hline Relative age rank within school year squared & $\begin{array}{l}-0.0026 \\
(0.0048)\end{array}$ & $\begin{array}{l}-0.0031 \\
(0.0049)\end{array}$ & $\begin{array}{l}-0.0021 \\
(0.0048)\end{array}$ & $\begin{array}{l}-0.0026 \\
(0.0049)\end{array}$ & $\begin{array}{c}0.0002 \\
(0.0028)\end{array}$ & $\begin{array}{c}0.0001 \\
(0.0028)\end{array}$ & $\begin{array}{c}0.0004 \\
(0.0028)\end{array}$ & $\begin{array}{c}0.0004 \\
(0.0028)\end{array}$ \\
\hline $\begin{array}{c}\text { joint significance test p-value baseline maturity } \\
\text { joint significance test } p \text {-value maturity }\end{array}$ & $\begin{array}{l}{[0.0057]} \\
{[0.0001]}\end{array}$ & $\begin{array}{l}{[0.0151]} \\
{[0.0027]} \\
\end{array}$ & $\begin{array}{l}{[0.0067]} \\
{[0.0001]} \\
\end{array}$ & $\begin{array}{l}{[0.0179]} \\
{[0.0028]} \\
\end{array}$ & $\begin{array}{l}{[0.5860]} \\
{[0.2127]}\end{array}$ & $\begin{array}{l}{[0.6675]} \\
{[0.4356]}\end{array}$ & $\begin{array}{l}{[0.5802]} \\
{[0.2254]}\end{array}$ & $\begin{array}{l}{[0.6416]} \\
{[0.4384]}\end{array}$ \\
\hline \multicolumn{9}{|l|}{ Whether in employment } \\
\hline Any academic qualification & $\begin{array}{r}0.2639 * * \\
(0.0031)\end{array}$ & $\begin{array}{r}0.2212 * * \\
(0.0676)\end{array}$ & $\begin{array}{r}0.2667 * * \\
(0.0031)\end{array}$ & $\begin{array}{r}0.2312 * * \\
(0.0660)\end{array}$ & $\begin{array}{r}0.1599 * * \\
(0.0024)\end{array}$ & $\begin{array}{r}0.2064 * * \\
(0.0542)\end{array}$ & $\begin{array}{r}0.1642 * * \\
(0.0024)\end{array}$ & $\begin{array}{r}0.2203 * * \\
(0.0541)\end{array}$ \\
\hline Relative age rank within school year & $\begin{array}{c}0.0007 \\
(0.0056)\end{array}$ & $\begin{array}{c}0.0016 \\
(0.0058)\end{array}$ & $\begin{array}{l}0.0001 \\
(0.0057)\end{array}$ & $\begin{array}{c}0.0009 \\
(0.0058)\end{array}$ & $\begin{array}{l}-0.0069 \\
(0.0040)\end{array}$ & $\begin{array}{l}-0.0077 \\
(0.0041)\end{array}$ & $\begin{array}{l}-0.0073 \\
(0.0041)\end{array}$ & $\begin{array}{r}-0.0082 * \\
(0.0042)\end{array}$ \\
\hline Relative age rank within school year squared & $\begin{array}{l}-0.0048 \\
(0.0051)\end{array}$ & $\begin{array}{l}-0.0054 \\
(0.0051)\end{array}$ & $\begin{array}{l}-0.0043 \\
(0.0051)\end{array}$ & $\begin{array}{l}-0.0048 \\
(0.0052)\end{array}$ & $\begin{array}{c}0.0048 \\
(0.0036)\end{array}$ & $\begin{array}{c}0.0052 \\
(0.0037)\end{array}$ & $\begin{array}{c}0.0051 \\
(0.0037)\end{array}$ & $\begin{array}{l}0.0056 \\
(0.0037)\end{array}$ \\
\hline $\begin{array}{c}\text { joint significance test } p \text {-value baseline maturity } \\
\text { joint significance test } p \text {-value maturity }\end{array}$ & $\begin{array}{l}{[0.0015]} \\
{[0.0002]}\end{array}$ & $\begin{array}{l}{[0.0046]} \\
{[0.0056]}\end{array}$ & $\begin{array}{l}{[0.0018]} \\
{[0.0002]}\end{array}$ & $\begin{array}{l}{[0.0057]} \\
{[0.0050]}\end{array}$ & $\begin{array}{l}{[0.0699]} \\
{[0.2157]}\end{array}$ & $\begin{array}{l}{[0.0490]} \\
{[0.3113]}\end{array}$ & $\begin{array}{l}{[0.0577]} \\
{[0.1748]}\end{array}$ & $\begin{array}{l}{[0.0351]} \\
{[0.2329]}\end{array}$ \\
\hline Regional dummies & 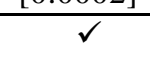 & $\frac{1000}{2}$ & & & $\checkmark$ & $\sqrt{100}$ & & \\
\hline Ethnic group dummies & $\checkmark$ & $\checkmark$ & & & $\checkmark$ & $\checkmark$ & & \\
\hline
\end{tabular}

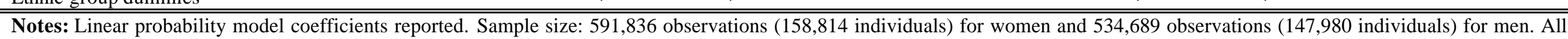

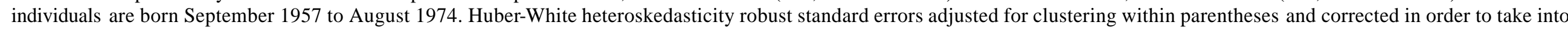

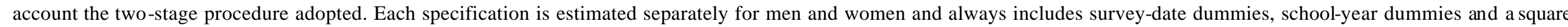

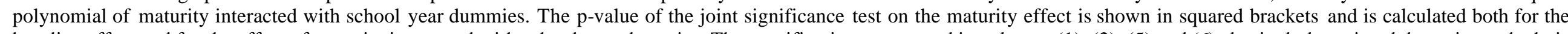

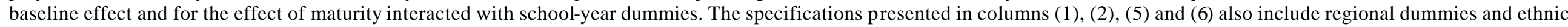
group dummies. First stage results according to the specification presented in footnote to Table 6. Symbols: ** significant at $1 \%$ level; * significant at $5 \%$ level. 
Table 8

OLS and TSLS estimates of the effect of having any academic qualifications by cohort and year for women and men

in England and Wales

\begin{tabular}{|c|c|c|c|c|c|c|c|c|}
\hline \multirow{4}{*}{ Impact of any academic qualification for } & \multicolumn{4}{|c|}{ Women } & \multicolumn{4}{|c|}{ Men } \\
\hline & \multicolumn{2}{|c|}{$\begin{array}{c}\text { Participation in the labour } \\
\text { market }\end{array}$} & \multicolumn{2}{|c|}{ Whether in employment } & \multicolumn{2}{|c|}{$\begin{array}{c}\text { Participation in the labour } \\
\text { market }\end{array}$} & \multicolumn{2}{|c|}{ Whether in employment } \\
\hline & $(1)$ & $(2)$ & (3) & (4) & $(5)$ & $(6)$ & (7) & $(8)$ \\
\hline & OLS & TSLS & OLS & TSLS & OLS & TSLS & OLS & TSLS \\
\hline \multirow[t]{2}{*}{ Born $1957-1962$ in $1993-1996$} & $0.2010 * *$ & $0.1962 * *$ & $0.2173^{* *}$ & $0.2373 * *$ & $0.0713^{* *}$ & $0.0778 * *$ & $0.1682 * *$ & $0.1633^{* *}$ \\
\hline & $(0.0071)$ & $(0.0485)$ & $(0.0074)$ & $(0.0514)$ & $(0.0039)$ & $(0.0216)$ & $(0.0059)$ & $(0.0350)$ \\
\hline \multirow{2}{*}{ Born $1957-1962$ in $1997-2000$} & $0.1935^{* *}$ & $0.1841 * *$ & $0.2153^{* *}$ & $0.2127 * *$ & $0.0939 * *$ & $0.0916^{* *}$ & $0.1509 * *$ & $0.1364 * *$ \\
\hline & $(0.0073)$ & $(0.0487)$ & $(0.0076)$ & $(0.0515)$ & $(0.0048)$ & $(0.0264)$ & $(0.0059)$ & $(0.0334)$ \\
\hline \multirow[t]{2}{*}{ Born $1957-1962$ in $2001-2003$} & $0.1877 * *$ & $0.1958 * *$ & $0.1983^{* *}$ & $0.2238 * *$ & $0.1060 * *$ & $0.1744 * *$ & $0.1318 * *$ & $0.1744 * *$ \\
\hline & $(0.0085)$ & $(0.0533)$ & $(0.0088)$ & $(0.0563)$ & $(0.0060)$ & $(0.0321)$ & $(0.0068)$ & $(0.0377)$ \\
\hline \multirow[t]{2}{*}{ Born $1963-1968$ in $1993-1996$} & $0.2789 * *$ & $0.2911 * *$ & $0.3070 * *$ & $0.3366 * *$ & $0.0646^{* *}$ & $0.0566^{* *}$ & $0.1822 * *$ & $0.1821 * *$ \\
\hline & $(0.0077)$ & $(0.0531)$ & $(0.0078)$ & $(0.0568)$ & $(0.0040)$ & $(0.0206)$ & $(0.0065)$ & $(0.0373)$ \\
\hline \multirow[t]{2}{*}{ Born $1963-1968$ in $1997-2000$} & $0.2516^{* *}$ & $0.2821 * *$ & $0.2874 * *$ & $0.3146 * *$ & $0.0925^{* *}$ & $0.0521 *$ & $0.1756^{* *}$ & $0.1461 * *$ \\
\hline & $(0.0081)$ & $(0.0529)$ & $(0.0083)$ & $(0.0560)$ & $(0.0049)$ & $(0.0265)$ & $(0.0064)$ & $(0.0366)$ \\
\hline \multirow[t]{2}{*}{ Born $1963-1968$ in $2001-2003$} & $0.2248 * *$ & $0.1626 * *$ & $0.2448 * *$ & $0.1776^{* *}$ & $0.1014 * *$ & $0.0784 *$ & $0.1354 * *$ & $0.1320 * *$ \\
\hline & $(0.0095)$ & $(0.0607)$ & $(0.0098)$ & $(0.0636)$ & $(0.0062)$ & $(0.0312)$ & $(0.0072)$ & $(0.0380)$ \\
\hline Born 1969-1974 in 1993-1996 & $0.3593 * *$ & $0.3311 * *$ & $0.3844 * *$ & $0.3447 * *$ & $0.0738 * *$ & $0.1299 * *$ & $0.1902 * *$ & $0.2900 * *$ \\
\hline \multirow[t]{2}{*}{ Born $1969-1974$ in $1997-2000$} & $0.3366^{* *}$ & $0.3349 * *$ & $0.3758 * *$ & $0.3716 * *$ & $0.0965^{* *}$ & $0.1456^{* *}$ & $0.1826^{* *}$ & $0.2760 * *$ \\
\hline & $(0.0098)$ & $(0.0593)$ & $(0.0099)$ & $(0.0632)$ & $(0.0061)$ & $(0.0296)$ & $(0.0080)$ & $(0.0418)$ \\
\hline \multirow[t]{2}{*}{ Born $1969-1974$ in $2001-2003$} & $0.3064 * *$ & $0.3242 * *$ & $0.3354 * *$ & $0.3614 * *$ & $0.1210^{* *}$ & $0.1386^{* *}$ & $0.1771 * *$ & $0.2079 * *$ \\
\hline & $(0.0107)$ & $(0.0642)$ & $(0.0109)$ & $(0.0677)$ & $(0.0073)$ & $(0.0312)$ & $(0.0087)$ & $(0.0398)$ \\
\hline Regional dummies & $\checkmark$ & $\checkmark$ & & & $\checkmark$ & $\checkmark$ & & \\
\hline Ethnic-group dummies & $\checkmark$ & $\checkmark$ & & & $\checkmark$ & $\checkmark$ & & \\
\hline
\end{tabular}

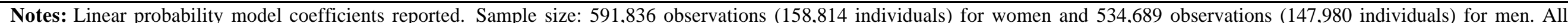

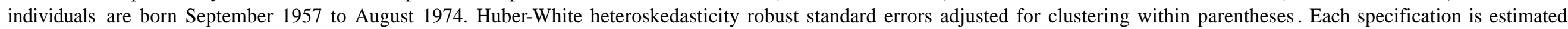

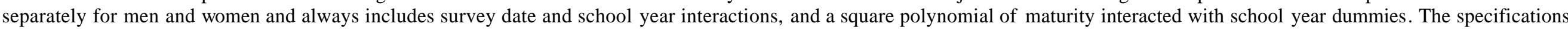

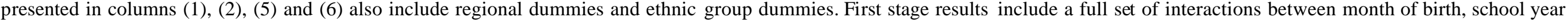
and survey date. Symbols: ** significant at $1 \%$ level; * significant at $5 \%$ level. 
Table 9

Heterogeneity of the effect of obtaining an academic qualification across potential subpopulations

\begin{tabular}{|c|c|c|c|c|c|}
\hline & & $\begin{array}{c}\text { Participation } \\
\text { in the labour } \\
\text { market }\end{array}$ & $\begin{array}{l}\text { Whether in } \\
\text { employment }\end{array}$ & $\begin{array}{c}\text { Potential } \\
\text { Subpopulations }\end{array}$ & Proportions \\
\hline & \multicolumn{5}{|l|}{ Women } \\
\hline & & \multicolumn{4}{|c|}{ Full sample } \\
\hline (1) & MTE: Never-Complier & 0.1024 & 0.1356 & Never educated & $16.7 \%$ \\
\hline (2) & LATE-IV & 0.0967 & 0.1282 & Compliers & $3.3 \%$ \\
\hline (3) & MTE: Complier-Always & 0.0912 & 0.1211 & Always educated & $80.0 \%$ \\
\hline (4) & ATE: $?_{1}-?_{0}$ & 0.0435 & 0.0592 & & \\
\hline \multirow[t]{2}{*}{ (5) } & OLS & 0.2079 & 0.2285 & & \\
\hline & & \multicolumn{4}{|c|}{ No post-16 academic qualification } \\
\hline (1) & MTE: Never-Complier & 0.0481 & 0.0469 & Never educated & $23.1 \%$ \\
\hline (2) & LATE-IV & 0.0408 & 0.0392 & Compliers & $4.5 \%$ \\
\hline (3) & MTE: Complier-Always & 0.0332 & 0.0314 & Always educated & $72.4 \%$ \\
\hline (4) & ATE: $?_{1}-?_{0}$ & 0.0608 & 0.0600 & & \\
\hline \multirow[t]{3}{*}{ (5) } & OLS & 0.1482 & 0.1565 & & \\
\hline & Men & & & & \\
\hline & & \multicolumn{4}{|c|}{ Full sample } \\
\hline (1) & MTE: Never-Complier & 0.1525 & 0.2706 & Never educated & $20.9 \%$ \\
\hline (2) & LATE-IV & 0.1563 & 0.2736 & Compliers & $2.9 \%$ \\
\hline (3) & MTE: Complier-Always & 0.1601 & 0.2765 & Always educated & $76.2 \%$ \\
\hline (4) & ATE: $?_{1}-?_{0}$ & 0.2161 & 0.3199 & & \\
\hline \multirow[t]{2}{*}{ (5) } & OLS & 0.0908 & 0.1649 & & \\
\hline & & \multicolumn{4}{|c|}{ No post-16 academic qualification } \\
\hline (1) & MTE: Never-Complier & 0.1604 & 0.2438 & Never educated & $29.2 \%$ \\
\hline (2) & LATE-IV & 0.1633 & 0.2469 & Compliers & $4.3 \%$ \\
\hline (3) & MTE: Complier-Always & 0.1662 & 0.2499 & Always educated & $66.5 \%$ \\
\hline (4) & ATE: $?_{1}-?_{0}$ & 0.1864 & 0.2713 & & \\
\hline (5) & OLS & 0.0871 & 0.1551 & & \\
\hline
\end{tabular}

Note: Sample of individuals born November to April (included). For both the full sample of men and women and for the subsample of individuals with less than A-levels the table presents: (1) the marginal treatment effect for the estimated heterogeneity threshold between the never educated and the compliers, (2) the instrumental variable estimate, i.e. the Local Average Treatment Effect for the samp le of compliers, (3) the marginal treatment effect for the estimated heterogeneity threshold between the compliers and the always educated, (4) the average treatment effect for the whole population, and (5) the ordinary least squares. Compliers are defined as individuals who appear to be induced to gain an academic qualification as a result of instrument treatment (being born in February or March, i.e. compelled to stay beyond Easter). MTEs and ATE are based on the joint normality assumption, using first stage estimates from a probit model of qualification attainment. For simplicity, employment and activity are treated as if they were continuous variables. 
Figure 1

Proportion of women with any qualification by month of birth in England and Wales

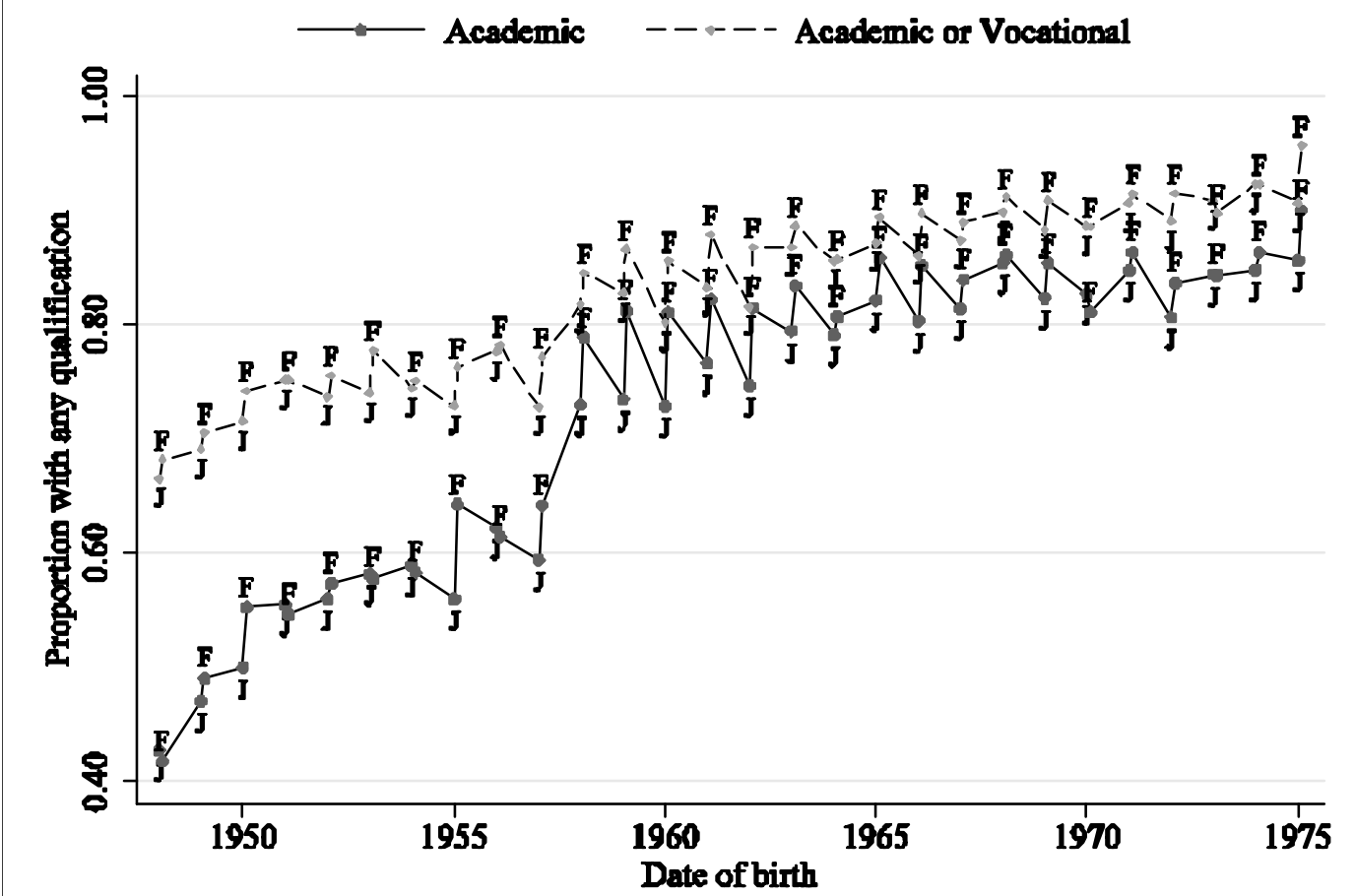

Notes: Cohort profile of women who attain any academic qualification (continuous line) or any academic or vocational qualification (discontinuous line) for sample born in January (J) or February (F). 
Figure 2

Proportion of men with any qualification by month of birth in England and Wales

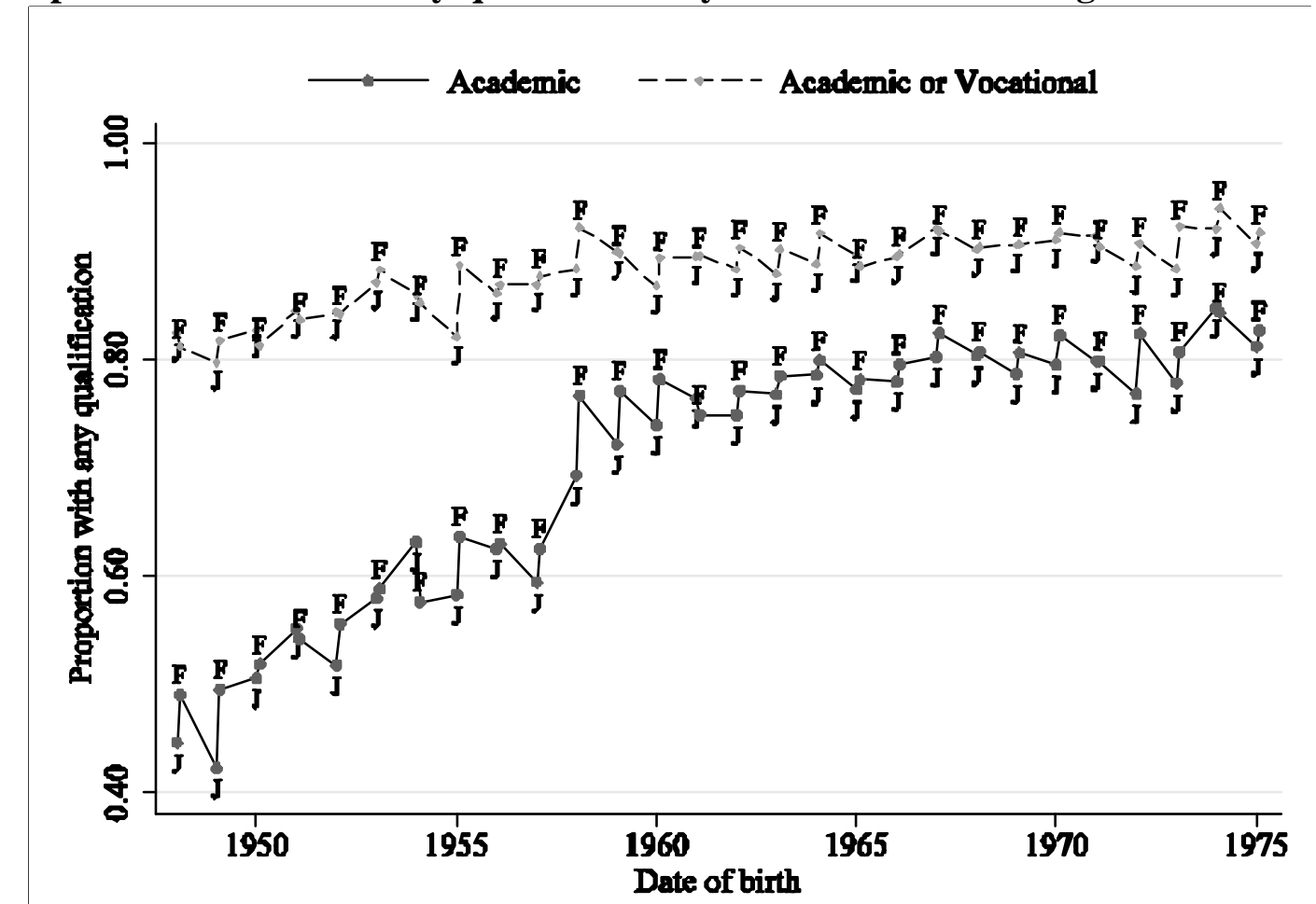

Notes: Cohort profile of men who attain any academic qualification (continuous line) or any academic or vocational qualification (discontinuous line) for sample born in January (J) or February (F). 
Figure 3

Proportion of women attaining level of academic qualification in England and Wales, by date of birth

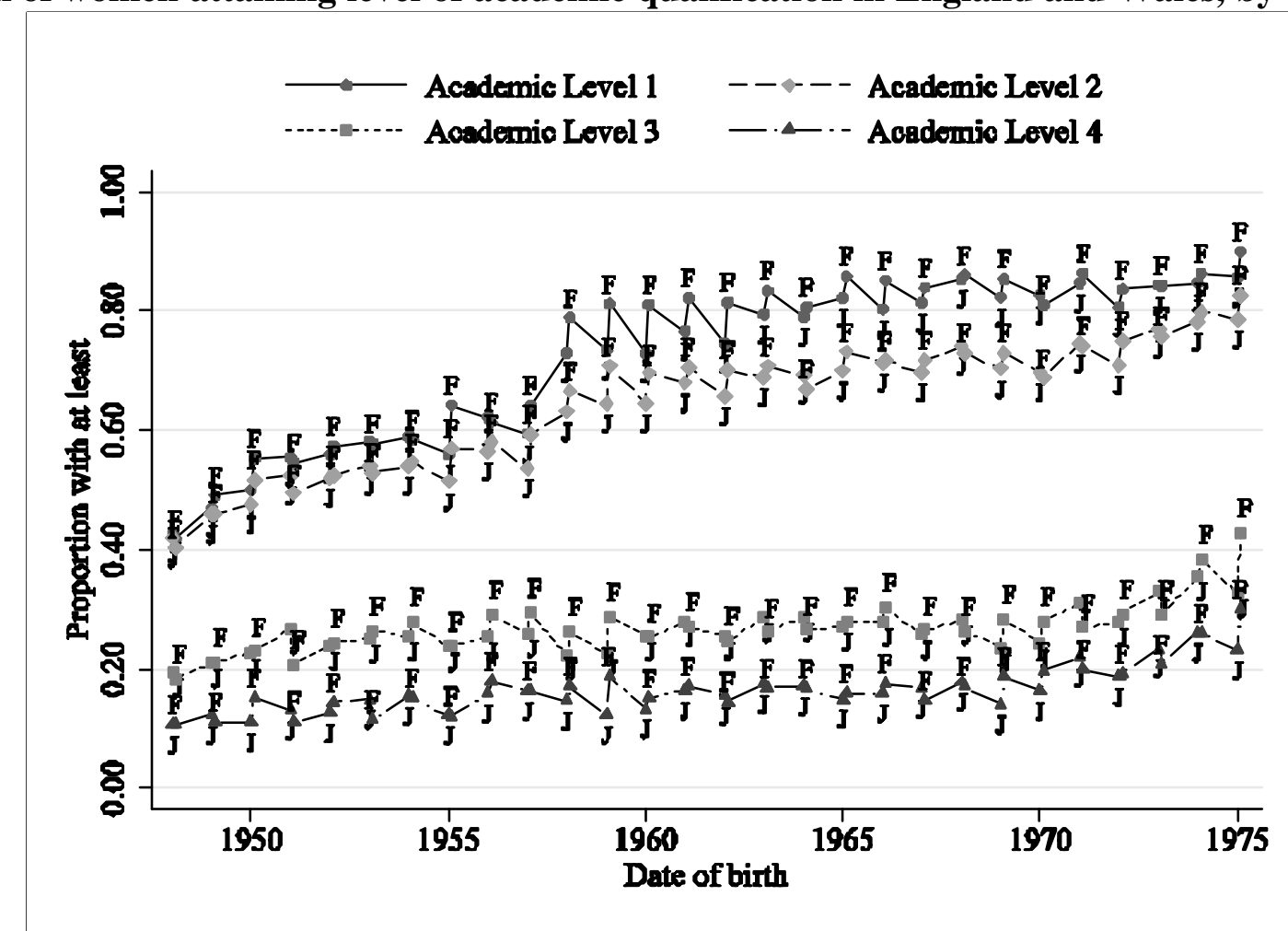

Notes: Cohort profile of the proportion of women who have at least attained the academic qualification level shown for sample born in January (J) or February (F). 
Figure 4

Proportion of men attaining level of academic qualification in England and Wales, by date of birth

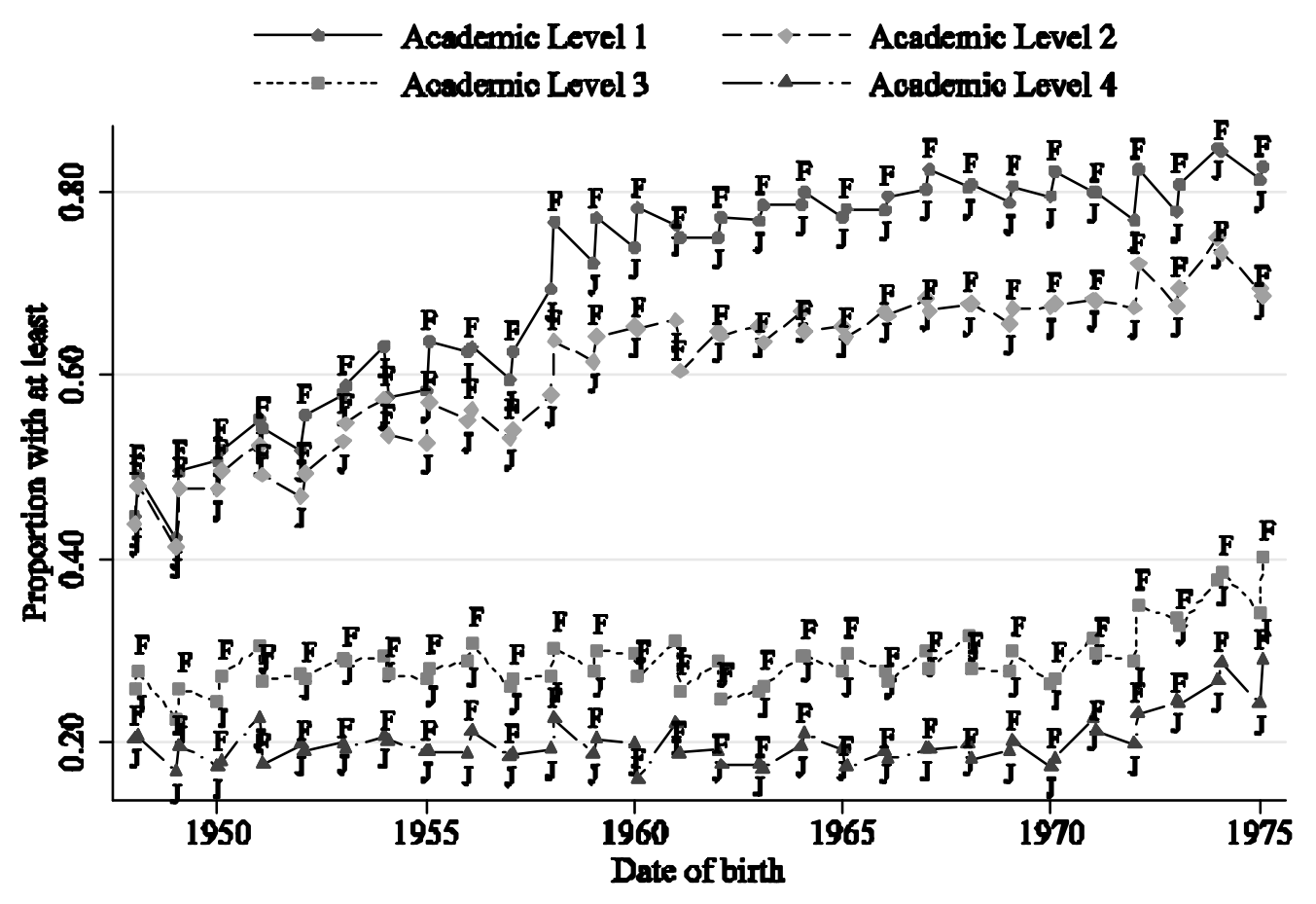

Notes: Cohort profile of the proportion of men who have at least attained the academic qualification level shown for sample born in January (J) or February (F). 
Figure 5

The effect of school entry and exit rules on women's academic attainment in England and Wales

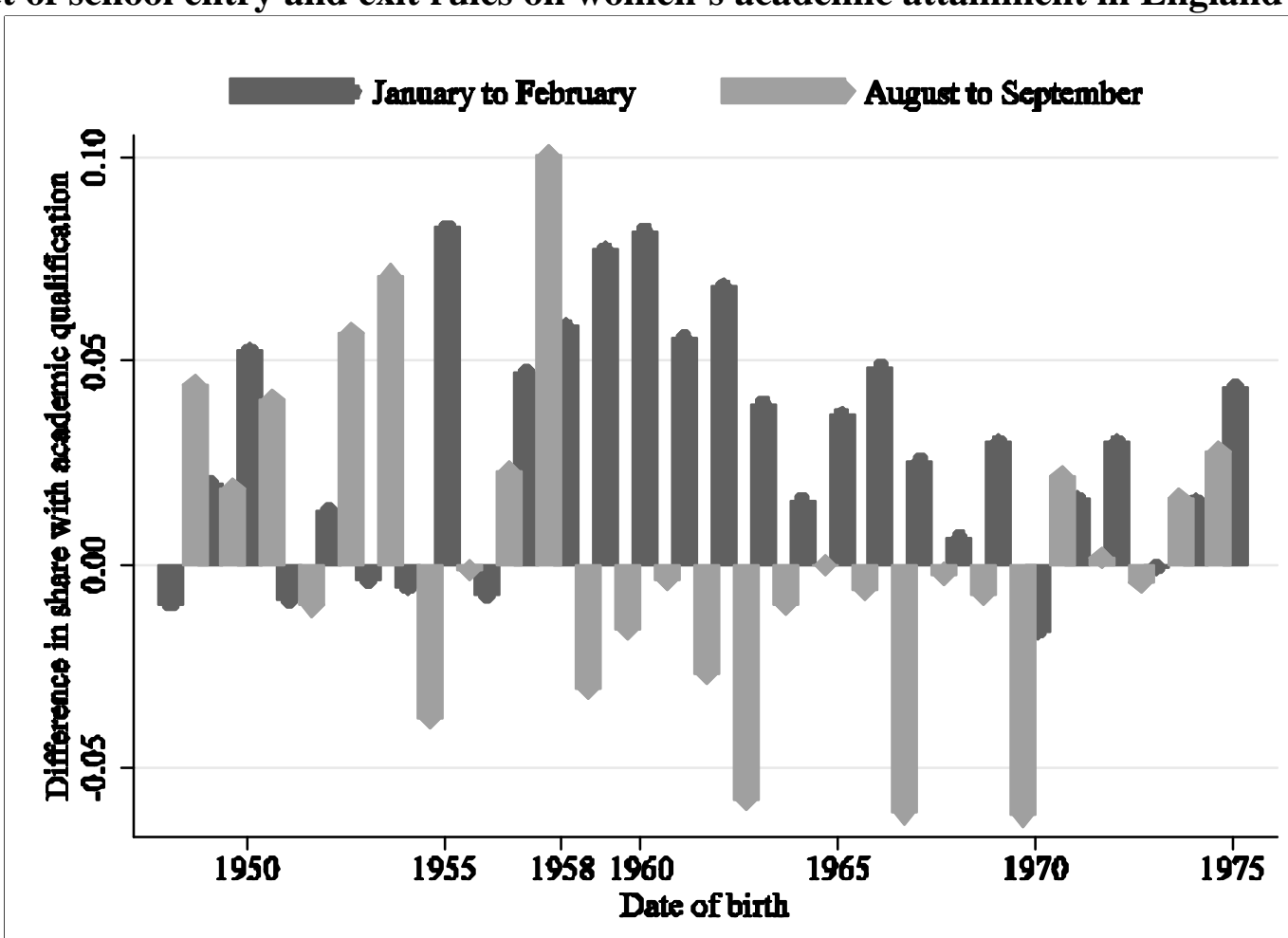

Notes: Dark bars depict the difference in the proportion of women with any academic qualification between those born in February relative to those born one month earlier (January $=$ entitled to leave in Easter). Light shaded bars depict the September-August difference (reflecting combined effect of class entry and Easter leaving rules). 
Figure 6

The effect of school entry and exit rules on men's academic attainment in England and Wales

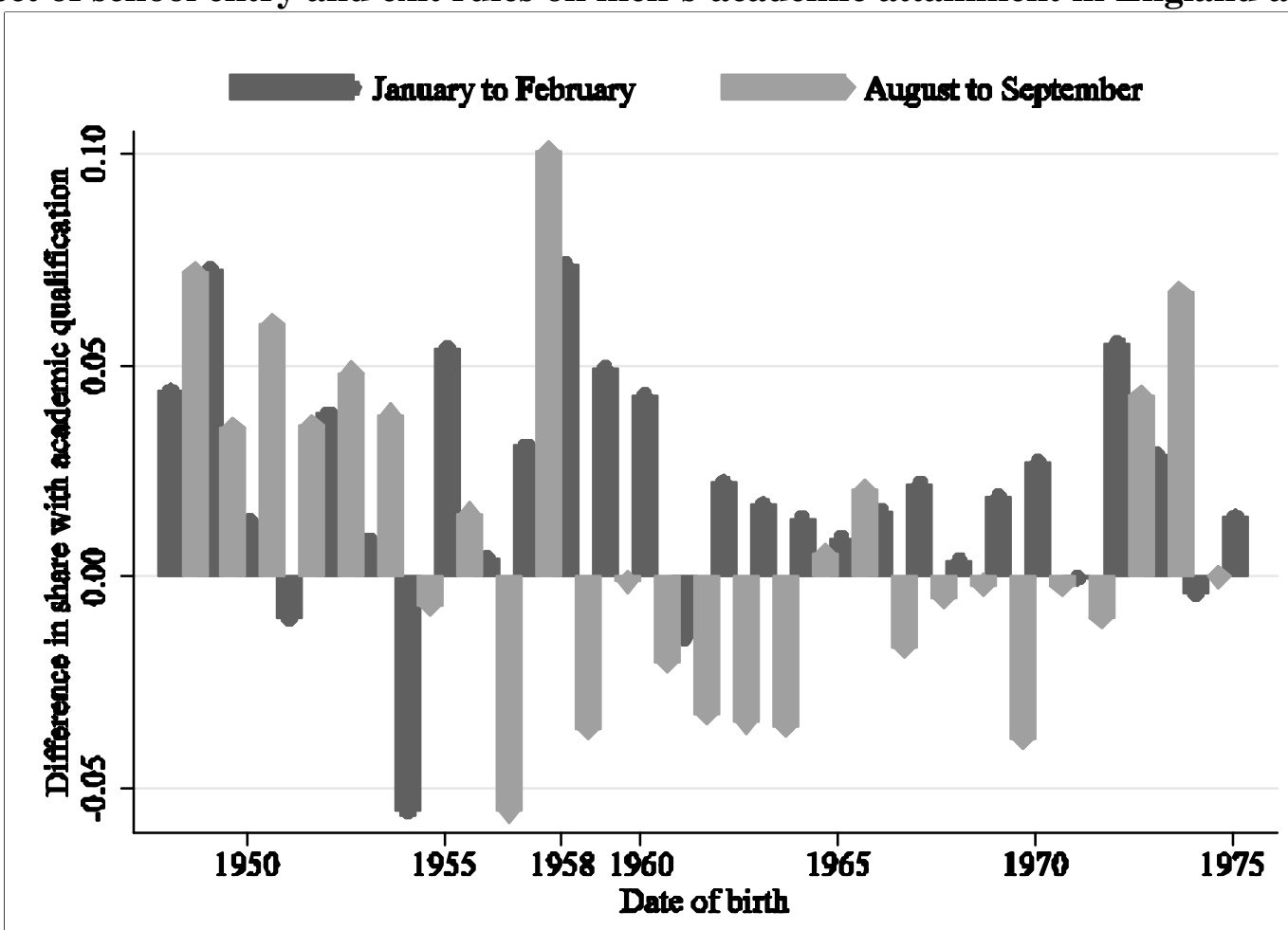

Notes: Dark bars depict the difference in the proportion of men with any academic qualification between those born in February relative to those born one month earlier (January = entitled to leave in Easter). Light shaded bars depict the September-August difference (reflecting combined effect of class entry and Easter leaving rules). 
Figure 7

Effect of month of birth on the probability of achieving an academic qualification for women in England and Wales

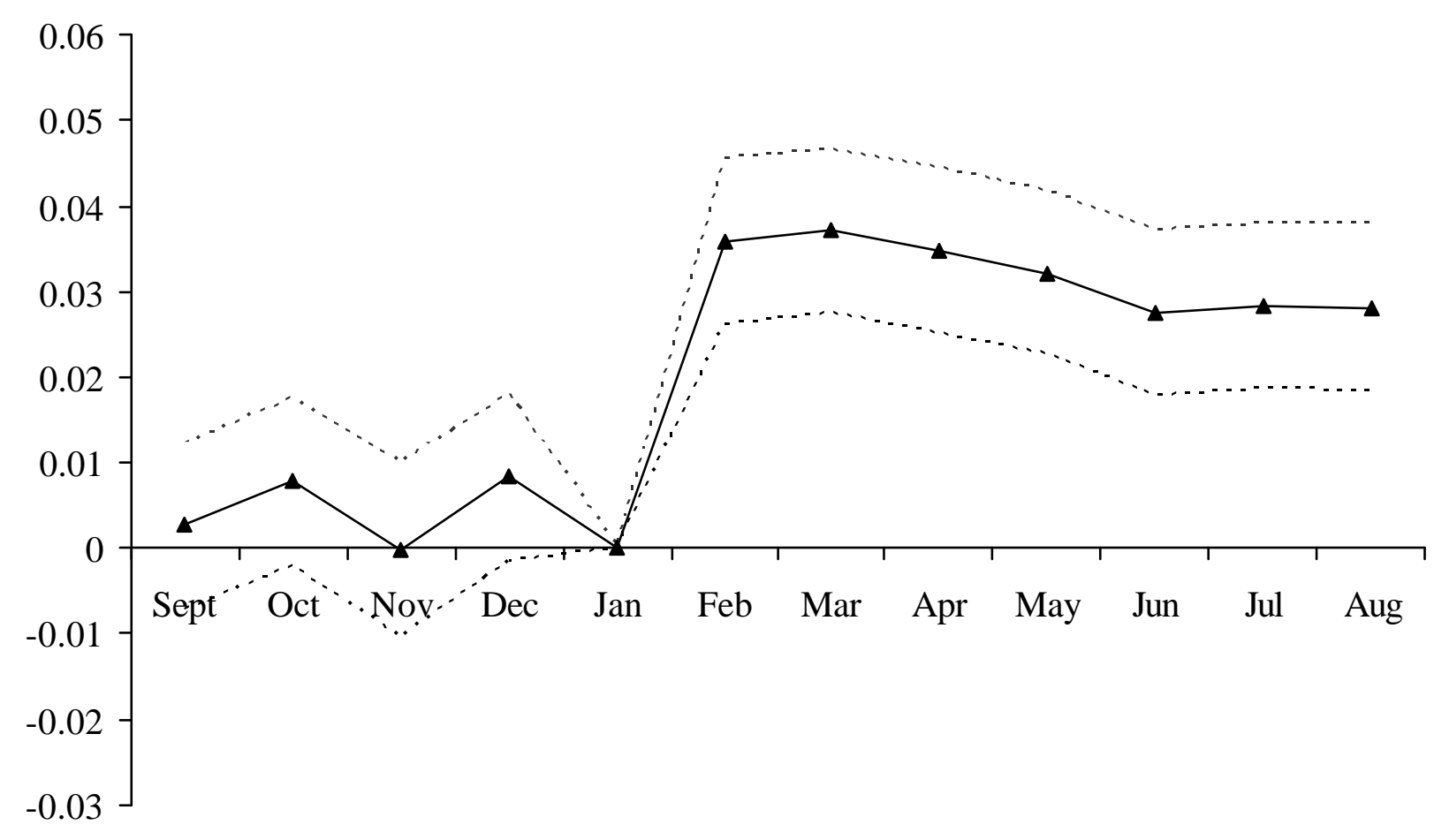

Notes: Estimated effect of month of birth on the probability of achieving an academic qualification for women. Effects are estimated by a linear probability model through OLS. Sample size: 591,836 observations (158,814 individuals). All individuals are born September 1957 to August 1974 . Confidence intervals obtained using Huber-White heteroskedasticity robust standard errors adjusted in order to take into account the presence of multiple observations for each individual shown by discontinuous lines. Except for the month dummies, the model is specified as in Table 3 and includes survey date dummies, school year dummies, regional dummies, ethnic group dummies, and an intercept. The omitted month is January. 
Figure 8

Effect of month of birth on the probability of achieving an academic qualification for men in England and Wales

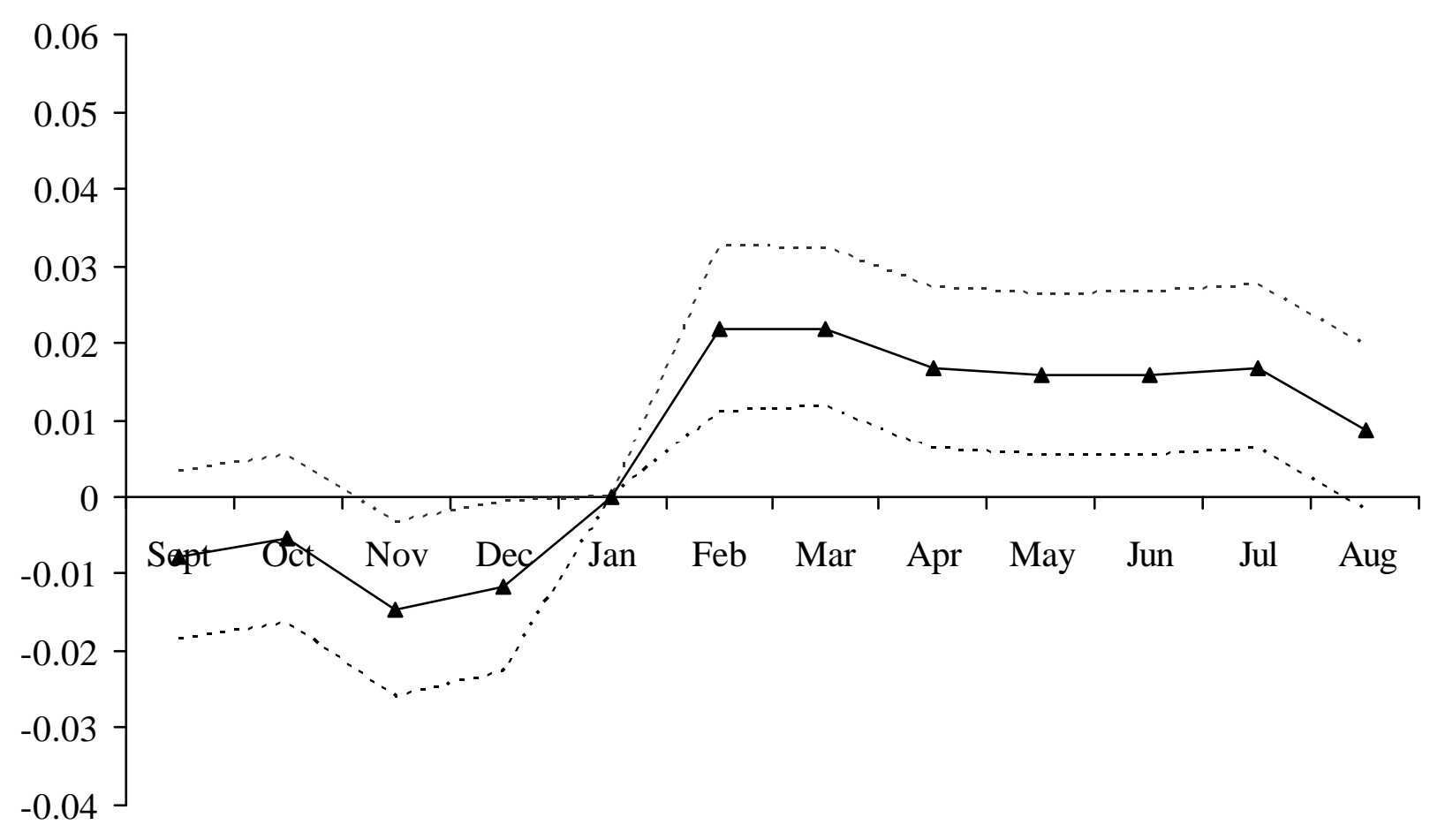

Notes: Estimated effect of month of birth on the probability of achieving an academic qualification for men. Effects are estimated by a linear probability model through OLS. Sample size: 534,689 observations (147,980 individuals). All individuals are born September 1957 to August 1974. Confidence intervals obtained using Huber-White heteroskedasticity robust standard errors adjusted in order to take into account the presence of multiple observations for each individual shown by discontinuous lines. Except for the month dummies, the model is specified as in Table 3 and includes survey date dummies, school year dummies, regional dummies, ethnic group dummies, and an intercept. The omitted mo nth is January. 
Figure 9

Proportions of active and employed women by month of birth in England and Wales

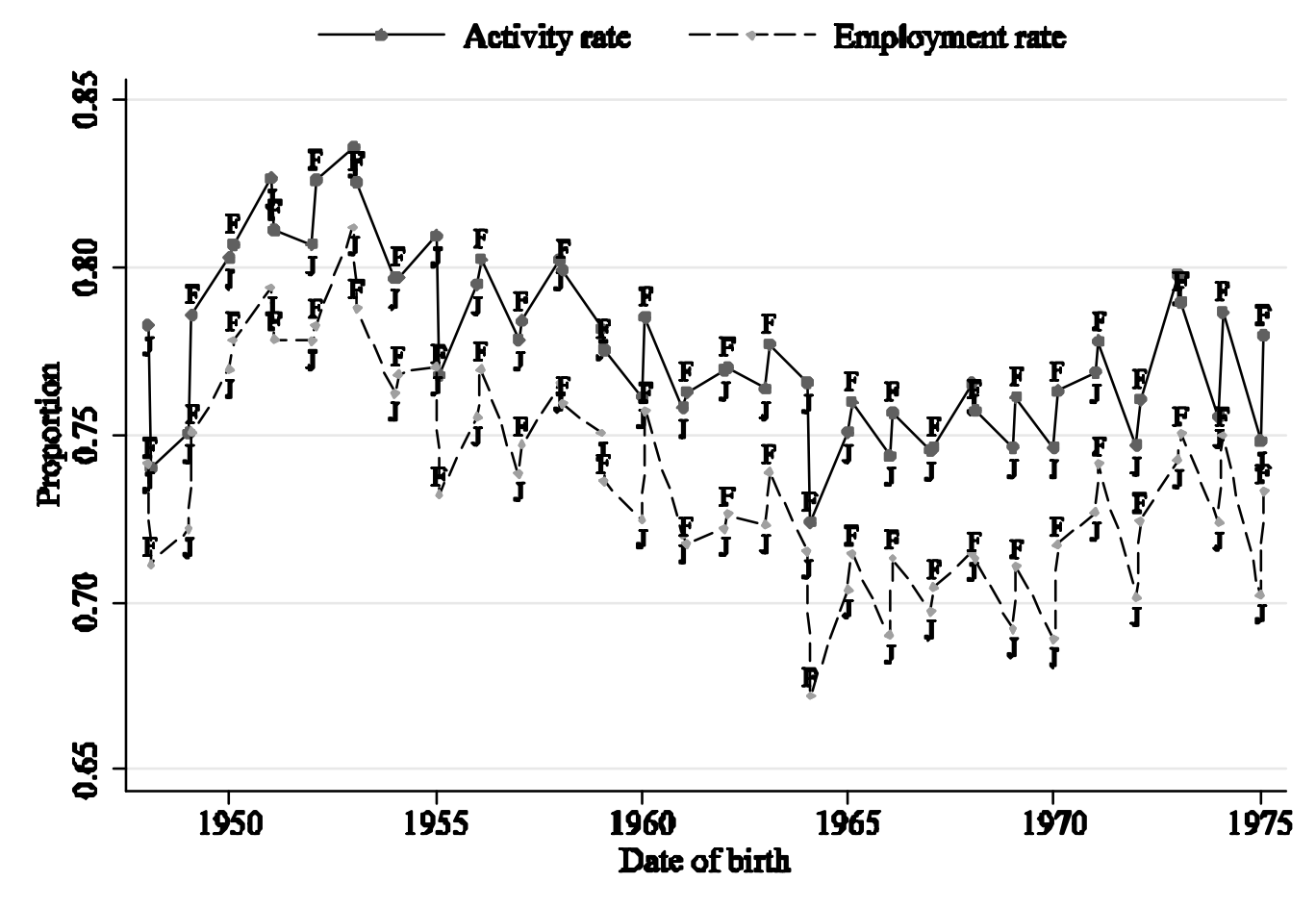

Notes: Cohort profile of women participating in the labour market or employed for sample born in January (J) or February (F). 
Figure 10

Proportions of active and employed men by month of birth in England and Wales

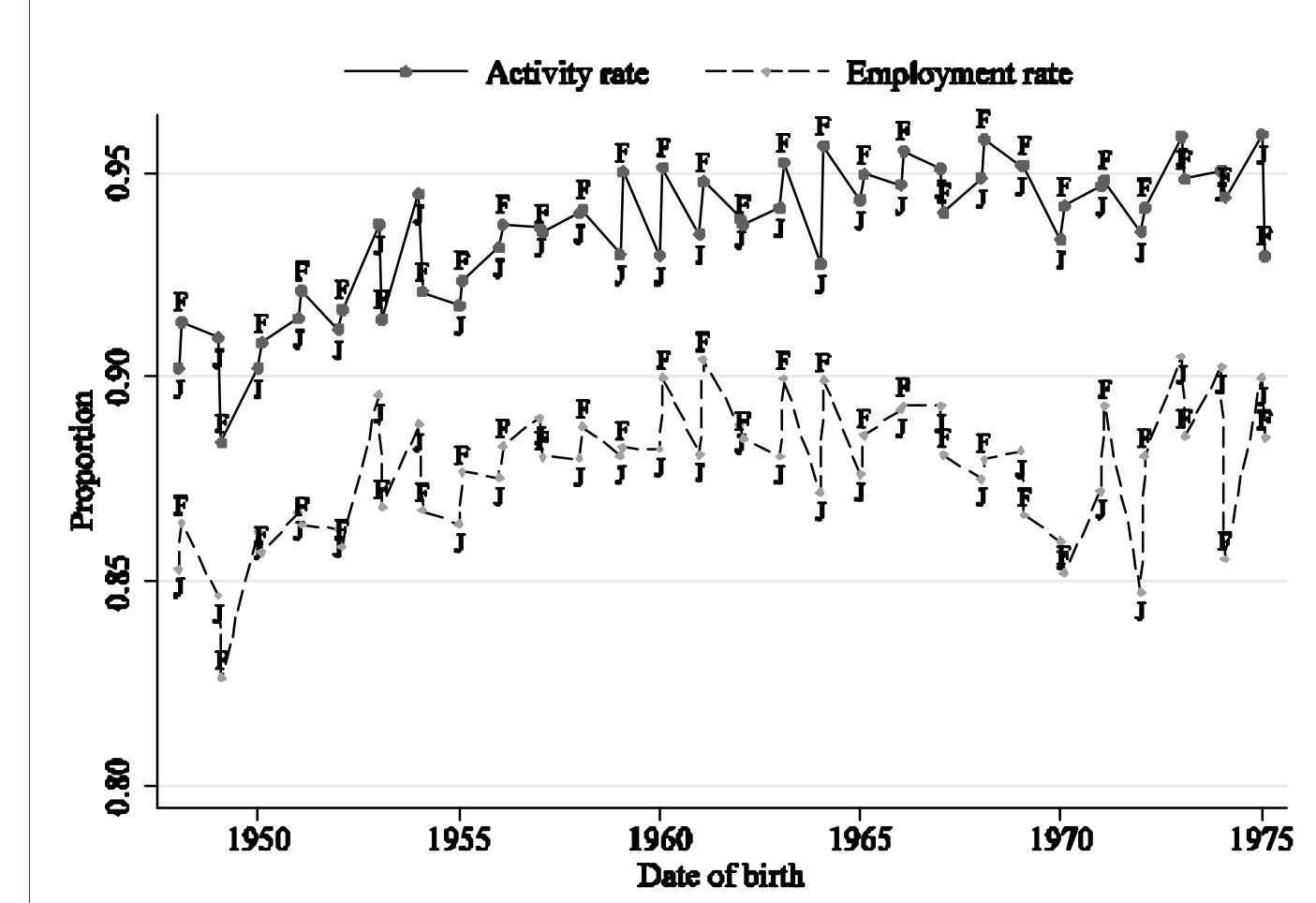

Notes: Cohort profile of men participating in the labour market or employed for sample born in January (J) or February (F). 


\section{APPENDIX 1}

\section{A. SCHOOL LEAVING AGE LEGISLATION IN ENGLAND AND WALES}

\section{Education Act 1962: relevant extracts from Section 9}

Applies to 15 year-old individuals in 1963, i.e. people born in 1947 or afterwards.

(2) If he attains that age on any date from the beginning of September to the end of January, he shall be deemed not to have attained that age until the end of the appropriate spring term at this school.

(3) If he attains that age on any date on or after the beginning of February but before the end of the appropriate summer term at his school, he shall be deemed not to have attained that age until the end of that summer term.

(4) If he attains that age on any date between the end of the appropriate summer term at this school and the beginning of September next following the end of that summer term (whether another term has then begun or not) he shall be deemed to have attained that age at the end of that summer term.

[...]

(7) In this section, "the appropriate spring term", in relation to a person, means the last term at this school which ends before the month of May next following the date on which he attains the age in question, and "the appropriate summer term" [...] means the last term at this school which ends before the month of September next following that date [...].

\section{Education School-leaving Act 1976: relevant extracts from Section 1}

Subsections (3) and (4) in Section 9 of the Education Act of 1962 were substituted by the following subsections of Section 1 of the Education School leaving Act 1976 in order to give a more precise meaning to the notion of school leaving dates, particularly for those born after the end of January.

(3) If he attains that age after the end of January but before the next May schoolleaving date, he shall be deemed not to have attained that age until that date.

(4) If he attains that age after the May school-leaving date and before the beginning of September next following that date, he shall be deemed to have attained that age on that date.

A new subsection was added at the end of Section 9 of the Education Act of 1962, according to which:

(8) In this section "the May school-leaving date" means the Friday before the last Monday in May”.

\section{Circular number 11/97, following the Education Act 1996}

Under section 1(4) of the Education Act 1996, the circular eliminates school leaving age discontinuity for all children born after1981.

[...] A new single school leaving date has been set for 1998 and all subsequent years. This is the last Friday in June in the school year in which a child reaches age 16. In 1998 the date is 26 June. 
The Government's intention in bringing in this legislation is to ensure that a child's education continues at least until the summer which completes eleven years of compulsory education. The date chosen coincides with the end of the main examination period. It should therefore enable more children, whether or not on a school's roll, to be entered for and to achieve GCSE, GNVQ and other qualifications. The date is binding even on children who are not entered for examinations and assessments. The duty is to ensure that all children benefit from suitable education, at school or otherwise, until the legal date.

Example of letter to be sent to parents of pupils formerly eligible to leave at Easter:

Dear Parent

School Leaving Date for 16 Year Olds

On ............, your son/daughter will reach age 16.

In previous years your son/daughter would have been eligible to leave school at the end of the Spring term (i.e. the Easter holidays) following his/her sixteenth birthday.

The Government has now introduced a single school leaving date. This will be the last Friday in June in the school year in which a pupil reaches age 16 (26 June 1998). This will mean that your son/daughter will be required to remain at school for the summer term, and cannot take up full-time employment until after the school leaving date.

The purpose of the new legislation is to ensure that more children gain useful qualifications, and benefit from high-quality work experience.

If you have any queries on how these arrangements will affect your child, please do not hesitate to contact the school.

Yours faithfully

Headteacher 